\title{
LA VIOLACIÓN INDIRECTA DE LA LEY SUSTANCIAL POR ERRORES DE HECHO EN CASACIÓN PENAL*
}

\section{THE INDIRECT VIOLATION OF THE SUBSTANTIAL LAW BY FACTUAL ERRORS IN CRIMINAL CASSATION}

\author{
Miguel Ángel Muñoz-García** \\ Fecha de recepción: 16 de febrero de 2016 \\ Fecha de aceptación: 24 agosto de 2016 \\ Disponible en línea: 30 de noviembre de 2016
}

\section{Para citar este artículo/To cite this article}

Muñoz-García, Miguel Ángel, La violación indirecta de la ley sustancial por errores de hecho en casación penal, 133 Vniversitas, 139-190 (2016).

http://dx.doi.org/10.11144/Javeriana.vj133.vils

doi:10.11144/Javeriana.vj133.vils

* Artículo de reflexión

** Abogado de la Pontificia Universidad Javeriana, Bogotá. Magíster en ciencias penales y criminológicas, Universidad Externado de Colombia, Bogotá. Litigante y consultor en materia penal, socio de la firma Idrobo Asociados S.A. Ha sido profesor de derecho penal en la Pontificia Universidad Javeriana, y es autor de varios textos académicos. Contacto: miguel. munoz@idroboasociados.com 


\section{RESUMEN}

El artículo revisa las causales de casación penal relacionadas con los errores de hecho en la apreciación probatoria. Específicamente, analiza las metodologías descritas por la Sala Penal de la Corte Suprema de Justicia. El objetivo es realizar una crítica de ellas y contextualizar su estructura y objetivos con la concepción de la verdad en el proceso penal, propia del modelo cognoscitivista de jurisdicción penal. De la revisión de este punto se deduce que el demandante debe proceder al análisis de la prueba afectada por el error in iudicando. Para ello, debe reconocer si hay una prueba ignorada, en lo que se conoce como falso juicio de existencia. Alternativamente, debe reconocerse su verdadera esencia, en el caso del falso juicio de identidad. Este análisis debe basarse en la sana crítica, integrar el acervo probatorio estudiado por los sentenciadores y considerar la trascendencia de los errores de hecho.

Palabras clave: Casación; verdad; falso juicio de existencia; falso juicio de identidad; sana crítica 


\section{ABSTRACT}

The paper reviews the causals of criminal cassation related with the factual errors in evidence examination. Specifically, it analyses the methodologies used by the Criminal Appeal of the Supreme Court of Justice. The objective is to make an analysis of them and contextualize their structures and objectives related with their concept of truth from the cognitive model in the criminal process. From the review it is pointed out that the applicant should analyse the test affected by the error in iudicando. In order to do this, it must be recognized if there is an ignored test, in what is known as false judgment of existence. Alternatively, it must be acknowledged their true essence in the case of false judgment of identity. It is expected that this analysis must be based on the "common knowledge", it must integrate the evidence collection studied by the judges and must consider the transcendence of the factual errors.

Keywords: Cassation; truth; false judgement of existence; false judgment of identity; rules of common knowledge

\section{SUMARIO}

INTRODUCCIÓN.- I. LA APRECIACIÓN DE LAS PRUEBAS EN CONJUNTO.- II. COMENTARIOS SOBRE LOS ERRORES DE HECHO.-A. El error de hecho por falso juicio de existencia.- B. El error de hecho por falso juicio de identidad.- C. El error de hecho por falso raciocinio.-III. EL ROL DE LA VERDAD EN LA CASACIÓN PENAL POR VÍA INDIRECTA.- CONCLUSIONES.- BIBLIOGRAFÍA. 


\section{INTRODUCCIÓN}

El objetivo de este artículo es formular algunas observaciones críticas relacionadas con la técnica que la jurisprudencia de la Sala de Casación Penal de la Corte Suprema de Justicia ha establecido para dar por sentado el correcto planteamiento de algunas causales propias del recurso extraordinario, como el falso juicio de existencia, el falso juicio de identidad y el falso raciocinio, errores de hecho que fundamentan en casación la violación indirecta de la ley sustancial. La teleología de estas causales se relaciona en sí con uno de los fines del proceso penal: la aproximación a la verdad entendida como correspondencia entre un enunciado normativo y una facticidad relevante para la aplicación de una norma jurídica, por lo que, en la fundamentación de los cargos, le corresponde al casacionista analizar la prueba afectada por el yerro, a partir de una valoración racional (es decir, conforme a las reglas de la sana crítica) de la misma para delimitar su existencia (en el caso del falso juicio de existencia) y su esencia (en el caso del falso juicio de identidad), y relacionar los restantes medios de prueba valorados por las instancias. Esta finalidad de la verdad como correspondencia, por lo tanto, encuentra en las causales de violación indirecta por errores de hecho en la apreciación probatoria, un remedio procesal extremo para proveer a su realización en la mayor medida posible, mediante la corrección de los errores in iudicando determinantes en el fallo de una incorrecta fijación de los hechos y, por consiguiente, de una errada aplicación de la ley. Se concluirá finalmente si, en efecto, esas metodologías indicadas por la Corte para el planteamiento de la violación indirecta y algunas prácticas frecuentes en la sustanciación de los fallos son convenientes para la realización del valor de la verdad como correspondencia.

Antes de entrar de lleno en el análisis de las causales, es imperativo abordar una definición del error de hecho, especie del género error in iudicando ${ }^{1}$, siguiendo la jurisprudencia de la Sala

1 Así denominaban los antiguos el vicio de juicio, el error de razonamiento por parte del juez, que puede ser de hecho o de derecho. Es de derecho cuando expresa un falso juicio de valor sobre la norma, y puede recaer sobre su existencia, su selección o su hermenéutica. "Es de hecho cuando expresa un falso juicio en torno a la prueba. La equivocación debe versar sobre la existencia material del medio probatorio o sobre su sentido fáctico. Se dice que hay error de hecho sobre la existencia de la prueba, cuando se ignoró a pesar de hallarse, o cuando se 
de Casación Penal de la Corte. El error de hecho expresa un falso juicio en torno a la prueba, por lo que el yerro puede versar sobre la existencia material del medio probatorio o sobre su sentido fáctico:

el error de hecho manifiesto, por su propia naturaleza y características, tiene qué ver con la tangibilidad de la prueba, tanto respecto a su existencia misma como en cuanto a la objetividad de su significación probatoria. Luego no puede en modo alguno originarse un error evidente de hecho en una simple disparidad de criterios en torno a la aptitud demostrativa de la prueba, como tampoco en una visión fragmentaria de los medios de persuasión allegados a un proceso².

\section{LA APRECIACIÓN DE LAS PRUEBAS EN CONJUNTO}

Las causales de violación indirecta de la ley sustancial por error de hecho por falso juicio de existencia (en sus modalidades de omisión o de suposición del medio probatorio) y por falso juicio de identidad, se encaminan a proveer la efectiva vigencia del principio de unidad de la prueba o de apreciación de las pruebas en conjunto, según el cual las pruebas deberán ser apreciadas en conjunto de conformidad con las reglas de la sana crítica $^{3}$, actividad que implica que el funcionario judicial debe exponer siempre el mérito que le asigne a cada prueba, tal como lo dispone el artículo 238 de la Ley 600 de $2000^{4}$. De igual manera, el artículo 380 de la Ley 906 de 2004 establece que los elementos materiales probatorios y la evidencia física se apreciarán en conjunto ${ }^{5}$.

creyó que existía en el proceso; y que lo hay sobre su sentido, cuando el hecho que la prueba recoge fue tergiversado por el fallador". FABIo CALDERón-Botero, Casación y revisión en materia penal, 14 (Librería del Profesional, Bogotá, 1985).

2 Corte Suprema de Justicia, Sala Penal, Proceso 9428, 2 de octubre de 1996, magistrado ponente Carlos Augusto Gálvez-Argote. CCXLV Gaceta Judicial, Tomo 2484, 95-108. Disponible en: http://190.24.134.97/WebRelatoria/csj/index.xhtml

3 “Apreciación global o de conjunto, la que como 'principio rector' se impera a efectuarse, no solo de los plurales medios de prueba obrantes en el investigativo, sino también apreciación en conjunto respecto del medio probático en sí mismo e individualmente considerado". GERMÁN PABÓN-Gómez, De la casación y la revisión penal en el Estado constitucional, social y democrático de derecho, 248 (Ediciones Doctrina y Ley, Bogotá, 2003).

4 Artículo 238. Apreciación de las pruebas. Las pruebas deberán ser apreciadas en conjunto, de acuerdo con las reglas de la sana crítica. El funcionario judicial expondrá siempre razonadamente el mérito que le asigne a cada prueba. Colombia, Ley 600 de 2000, por la cual se expide el Código de Procedimiento Penal, 44.097 Diario Oficial, 24 de julio de 2000. Disponible en: http://www.secretariasenado.gov.co/senado/basedoc/ley_0600_2000_pr004.html

5 Artículo 380. Criterios de valoración. Los medios de prueba, los elementos materiales proba- 
Por otro lado, es conveniente también mencionar el principio de necesidad de la prueba, el cual indica que las providencias que resuelvan de fondo un asunto deben estar plenamente soportadas en las pruebas que le suministran al juez el conocimiento de los hechos del caso, que obran en el proceso y fueron aportadas al mismo de manera legal y oportuna ${ }^{6}$, por lo que al juzgador le está vedado acudir a su conocimiento privado 7 . El artículo 372 de la Ley 906 de 2004 consagra este principio que se quiebra con el falso juicio de existencia, y en cuyo tenor dice: "las pruebas tienen por fin llevar al conocimiento del juez, más allá de duda razonable, los hechos y circunstancias materia del juicio y los de la responsabilidad penal del acusado como autor o partícipe".

El conjunto probatorio del proceso forma una unidad, y así debe ser examinado y apreciado por el juzgador, con el fin de confrontar las diversas pruebas, puntualizar su concordancia o discordancia, y concluir sobre el convencimiento que de ellas globalmente se forme ${ }^{8}$. Es este el denominado principio de unidad de la prueba $a^{9}$. Siguiendo al italiano Giovanni BRICHETTI, la prueba debe concebirse como una unidad en la multiplicidad:

La prueba es verdadera síntesis, verdadero sistema, verdadera constituidora de la unidad en la multiplicidad; no simple suma, coacervatio, de los datos singulares. Por tanto, el convencimiento debe considerarse en rigor como agrupación, como síntesis; no como una simple suma de ideas. La suma y la multiplicación

torios y la evidencia física, se apreciarán en conjunto. Los criterios para apreciar cada uno de ellos serán señalados en el respectivo capítulo. Colombia, Ley 906 de 2004, por la cual se expide el Código de Procedimiento Penal, 45.657 Diario Oficial, 31 de agosto de 2004. Disponible en: http://www.secretariasenado.gov.co/senado/basedoc/ley_0906_2004.html

6 De hecho, "dos son los soportes de este importante principio: iuxta allegata et probata iudex iudicare debet ("El juez debe sentenciar conforme a lo alegado y probado"), regla propia del proceso canónico; y el brocardo latino in iudicio quod non apparet non est ("lo que no aparece del juicio es como si no existiera")". Gustavo Cuello-Iriarte, Derecho probatorio y pruebas penales, 672 (Legis, Bogotá, 2008).

7 O sea, su saber privado, el no adquirido en el ejercicio de su actividad oficial, es decir, el obtenido por las pruebas efectuadas en el proceso.

8 Hernando Devis-Echandía, Compendio de derecho procesal, Tomo II, Pruebas judiciales, 110 (Editorial ABC, Bogotá, 1973).

9 "En un proceso no solo se recauda o aporta una prueba, sino que es normal que aparezcan varias, inclusive de la misma especie: en todos esos casos la necesidad de estudiar la prueba como un todo salta a la vista, estudio que se debe hacer buscando las concordancias y divergencias, a fin de lograr el propósito indicado". JaIro Parra-QuiJano, Manual de derecho probatorio, 8 (Ediciones Librería del Profesional, Bogotá, 2009). 
son simples agregados cuantitativos, y el concepto debe expresar, en cambio, una unidad orgánica ${ }^{10}$.

Hernando Devis-Echandía, siguiendo el clásico texto de François Gorphe Apreciación judicial de las pruebas (1947), explica cómo a través de los medios de prueba son percibidos los hechos mediante los órganos de los sentidos y un simple raciocinio ${ }^{11}$. Una vez lista la actividad perceptiva, el juzgador debe proceder a la representación o reconstrucción histórica de los hechos mediante un razonamiento mucho más complejo, sobre todo de manera conjunta, con especial cuidado de evitar lagunas u omisiones que trastruequen la realidad o la hagan cambiar de significado. Así,

El éxito de la valoración, y, por tanto, de la sentencia, depende también de la correcta y completa representación de los hechos, en la cual no debe omitirse ninguno, por accesorio que parezca, y deben coordinarse todos y colocarse en el sitio adecuado, para luego clasificarlos con arreglo a su naturaleza, al tiempo y a las circunstancias de la realidad histórica que se trata de reconstruir ${ }^{12}$.

Para una correcta valoración no se deben tener en cuenta unos medios y rechazar otros, ni apreciar cada medio de manera aislada. Tal como aconsejan John Henry Wigmore y François Gorphe, debe formarse el juez:

Un cuadro esquemático de los diversos medios de prueba, clasificándolos de la manera más lógica, relacionándolos entre sí, debido a sus conexiones más o menos estrechas, comparando los elementos de cargo con los de descargo respecto de cada hecho, a fin de comprobar si los unos neutralizan a los otros o cuáles prevalecen, de manera que al final se tenga un conjunto sintético, coherente y concluyente; todo eso antes de sacar conclusiones de ellos, de acuerdo con la gran regla cartesiana de proceder objetivamente, sin ideas preconcebidas, con desconfianza o duda provisional respecto de las varias hipótesis ${ }^{13}$.

10 Giovanni Brichetti, La "evidencia" en el derecho procesal penal, 9 (Ediciones Jurídicas EuropaAmérica, Buenos Aires, 1973).

11 "La simple comprobación de un objeto o de un acontecimiento se debe a un juicio, por elemental que sea". Hernando Devis-Echandía, Teoría general de la prueba judicial, Tomo I, 276 (Temis, Bogotá, 2006).

12 Hernando Devis-Echandía, Teoría general de la prueba judicial, Tomo I, 227 (Temis, Bogotá, 2006).

13 Hernando Devis-Echandía, Compendio de derecho procesal, Tomo II, Pruebas judiciales, 97-98 (Editorial ABC, Bogotá, 1973). 
Este proceso termina con el resultado de la prueba, para cuyo conocimiento no basta con examinar los diversos medios probatorios que concurren a producir el convencimiento en un sentido positivo o negativo sobre la existencia de un hecho determinado, toda vez que es indispensable tener en cuenta los medios aportados por la parte contraria, para tratar de desvirtuar el valor de convicción de los primeros ${ }^{14}$. El resultado de la prueba, finalmente, es la conclusión que infiere el juez con base en el conjunto de los medios aportados al proceso, sobre los hechos afirmados o negados en él. Para Gorphe, en conclusión:

Todo elemento de prueba tiende a producir una creencia o una duda. Por tanto, solo debemos formar una conclusión luego de haberlos considerado todos $y$ de haber pesado el valor de cada uno. Es preciso no omitir ninguno de sus aspectos parciales, ni estimarles con exceso ni juzgarlos despreciables a fin de que la conclusión resulte digna de fe y la convicción conforme a los hechos ${ }^{15}$.

Antes de iniciar el estudio de la jurisprudencia sobre los errores de hecho, es necesario hacer unas precisiones conceptuales, empezando con la noción misma de valoración, que se entiende como el ejercicio intelectual del juez encaminado a verificar los enunciados fácticos propuestos por las contrapartes, o a evaluar la correspondencia de los mismos con los hechos que describen sobre la base de la prueba obrante ${ }^{16}$. El juez está en la obligación de argumentar el sentido de su decisión con base en las pruebas debidamente decretadas y practicadas en el proceso, individualizándolas, relacionándolas como un todo, precisando su contenido particular, su vinculación con los enunciados fácticos sugeridos y su grado de confirmación; en definitiva, el juzgador debe dar las

14 Hernando Devis-Echandía, Teoría general de la prueba judicial, Tomo I, 243 (Temis, Bogotá, 2006).

15 Hernando Devis-Echandía, Teoría general de la prueba judicial, Tomo I, 290 (Temis, Bogotá, 2006).

16 José Luis Castillo-Alva, La motivación de la valoración de la prueba en materia penal, 126 (Grijley \& Estudio Penal Castillo Alva \& Abogados, Lima, 2013). Para el español Jordi NievAFENOLL, la valoración de la prueba es "la actividad de percepción por parte del juez de los resultados de la actividad probatoria que se realiza en el proceso. Y quede claro que en esa percepción queda incluido, como actividades conjuntas, tanto la extracción de esos resultados como el juicio racional del juez sobre dicha percepción, que es consustancial a la misma, y que es lo que tradicionalmente se ha definido como valoración de la prueba. Diferente de la valoración será la motivación, que será la puesta de manifiesto, normalmente por escrito, de esa percepción”. Jordi Nieva-Fenoll, La valoración de la prueba, 34 (Marcial Pons, Madrid, 2010). 
razones sobre las cuales edifica la conclusión de acreditación de determinados enunciados a partir de las pruebas disponibles en el proceso. La valoración de la prueba se produce una vez cerrado el acopio de los diversos medios de prueba, y tiene como finalidad determinar el grado de corroboración de las hipótesis planteadas en relación con los medios de prueba disponibles ${ }^{17}$.

\section{COMENTARIOS SOBRE LOS ERRORES DE HECHO}

\section{A. El error de hecho por falso juicio de existencia}

Sobre el error de hecho por falso juicio de existencia, la jurisprudencia de la Sala de Casación Penal de la Corte Suprema de Justicia ha establecido que este se presenta cuando el fallador omite apreciar el contenido de una prueba legalmente aportada al proceso, en lo que se denomina falso juicio por omisión, o cuando, por el contrario, acepta como probado un acontecimiento a partir de un medio de convicción que no forma parte del acervo probatorio, es decir, que no fue practicado ni aportado al proceso, variante esta que se conoce como falso juicio de existencia por suposición ${ }^{18}$.

En cuanto a la primera modalidad, el error de hecho suele descubrirse con la confrontación directa del acopio probatorio y las motivaciones del fallo; lo fundamental es examinar si el análisis excluyó el elemento probatorio o el hecho que este contiene, porque el yerro no se configura si en la sentencia, pese a no mencionarse expresamente el medio de convicción, se aborda su contenido, se valora el hecho que revela y se fija su alcance suasorio ${ }^{19}$. Este planteamiento de la Corte ampliamente reiterado, es razonable en la medida en que permite maximizar la efectividad del principio de unidad de la prueba, ya que esta como tal debe merecer el análisis

17 José Luis Castillo-Alva, La motivación de la valoración de la prueba en materia penal, 101 (Grijley \& Estudio Penal Castillo Alva \& Abogados, Lima, 2013).

18 Corte Suprema de Justicia, Sala Penal, Proceso 41800, 16 de julio de 2014, magistrado ponente Gustavo Enrique Malo-Fernández. Disponible en: http://190.24.134.97/WebRelatoria/csj/ index.xhtml

19 Corte Suprema de Justicia, Sala Penal, Proceso 41800, 16 de julio de 2014, magistrado ponente Gustavo Enrique Malo-Fernández. Disponible en: http://190.24.134.97/WebRelatoria/csj/ index.xhtml 
íntegro de su contenido para fijar la afirmación del hecho que se quiere demostrar.

No obstante, cuando se afirma que no puede predicarse un falso juicio de existencia por omisión cuando la prueba es apenas mencionada por el sentenciador ${ }^{20}$, se desconoce que la mención de una prueba es solo eso, y no una incorporación valorativa de su contenido que puede incluso lograrse sin que la prueba sea directamente mencionada; por supuesto, si la prueba no es relevante para la acreditación de los hechos objeto del debate probatorio, bien sea de los relevantes para afirmar o infirmar la conducta punible, la intrascendencia del medio no justifica esa atención expresa de su contenido que es lo deseable en principio, porque como bien lo ha dicho la Sala Penal en otras ocasiones, "en virtud del principio de selección probatoria, el juez no está obligado a hacer un examen exhaustivo de todos y cada uno de los elementos de persuasión incorporados al proceso, ni de todos y cada uno de los extremos asertivos, porque la decisión se haría interminable, sino que debe ocuparse únicamente de aquellos que considere importantes para la decisión a adoptar, de suerte que solo existirá error de hecho por omisión o supresión de prueba, cuando aparezca de manera clara que ese medio fue realmente ignorado siendo relevante para la resolución del asunto"21.

Por estas consideraciones, esta causal de casación debe enfocarse en la trascendencia de la prueba omitida, y en el caso de que ese medio probatorio omitido revista suficiente importancia para acreditar algún hecho que hubiera variado las conclusiones del fallo, no es razonable inadmitir la censura por el hecho, en sí baladí, de que la prueba haya sido mencionada por el juzgador, porque una mera

20 "Es necesario precisar que la configuración de este error exige que el sentenciador haya prescindido de la prueba en forma absoluta en la motivación de la sentencia, de manera que la simple mención del medio probatorio en el fallo descarta su existencia, pues no se requiere que el juzgador elabore un amplio análisis sobre su eficacia demostrativa, en tanto basta que la incluya en la sentencia y si la menciona, significa que la prueba fue atendida. Cuando así ocurre, tiene dicho la Corte, si el juzgador valora o analiza en la sentencia de algún modo el medio probatorio supuestamente omitido, podrá afirmarse que incurre en una suerte de falso juicio de legalidad, convicción, identidad o raciocinio, según el caso, pero nunca en un error de existencia". Corte Suprema de Justicia, Sala Penal, Proceso 37626, 13 de noviembre de 2013, magistrado ponente José Leonidas Bustos-Martínez. Disponible en: http:/190.24.134.97/ WebRelatoria/csj/index.xhtml

21 Corte Suprema de Justicia, Sala Penal, Proceso 35161, 6 de marzo de 2013, magistrado ponente Julio Enrique Socha-Salamanca. Disponible en: http://190.24.134.97/WebRelatoria/csj/index. xhtml 
indicación de la prueba no significa que esta se haya incorporado al proceso valorativo probatorio del juez. En este punto, se quiere decir que la prueba no se incorpora con su mención, sino con el estudio de su contenido, convicción defendida por MICHELE TARUFFO quien critica la frecuencia con que los tribunales enuncian sin valorar ni justificar ${ }^{22}$. En la práctica, con esta posición de la Corte que se critica, esa indicación de la prueba sin análisis de su contenido obligaría las más de las veces al casacionista a plantear un falso juicio de identidad, causal que presupone, en una secuencia lógica, que la prueba fue tenida en cuenta, es decir, que no fue ignorada por el sentenciador, pero que no fue valorada en su contenido material por su extensivo (¡o casi total!) cercenamiento.

Lo correcto es que la jurisprudencia de la Corte retome un planteamiento simple, pero efectivo y coherente de cara a la lógica de las causales de falso juicio de existencia y de falso juicio de identidad: el hecho de que se soslaye la prueba con su mención genérica configura el error de hecho por falso juicio de existencia, ya que en este caso el juez no le dedica la debida atención que le impone la labor de apreciación del caudal probatorio. Esta observación crítica coincide con la exigencia de motivación racional de las pruebas en conjunto, que en esta causal del recurso extraordinario debe ser vigilada por la Corte de Casación, ya que la mera enunciación de las pruebas ignorando su contenido sustancial implica una violación del deber de motivar las resoluciones judiciales, para que puedan ser controlables de forma racional ex post ${ }^{23}$.

22 Para Michele TARuffo, es claro que al juez le asiste el deber de motivar de manera puntual y concreta los elementos de prueba, como lo ha recordado la jurisprudencia italiana en sede de casación, siendo en ocasiones evidente que el juez no justifica la valoración de la prueba y se queda en el plano de la enunciación. Constituye, por lo tanto, un abuso de la libre convicción judicial el hecho de que el juez no explique su ejercicio valorativo y está difundida la costumbre - a veces avalada por el mismo tribunal de casación - de pensar que no se requiere una motivación analítica y completa sobre las pruebas, situación que genera la violación del deber de motivar. Michele Taruffo, La valutazione della prova. Prova libera e prova legale. Prove e argomenti di prova, 108 Quaderni del Consiglio Superiore della Magistratura, La prova nel Processo Civile, Volume Secondo, 423-446, 431 (1999). Disponible en: http://www.csm.it/ quaderni/quad_108/quad_108_25.pdf. En España, el profesor JAVIER SÁNCHEZ-VERA GómEZTRELLES también plantea la necesidad de plena motivación sobre qué pruebas soportan las afirmaciones de los hechos, sin que sea viable que el juzgador se quede en la mera presentación en bruto del resultado de la práctica probatoria. JAVIER SÁnChEZ-Vera Gómez-Trelles, Variaciones sobre la presunción de inocencia. Análisis funcional desde el derecho penal, 117 (Marcial Pons, Madrid, 2012).

23 José Luis Castillo-Alva, La motivación de la valoración de la prueba en materia penal, 389 (Grijley \& Estudio Penal Castillo Alva \& Abogados, Lima, 2013). Aquí partimos de la idea 
Es frecuente que los casacionistas omitan una regla jurisprudencial, que suele olvidarse por el excesivo enfoque que les merece la sentencia de segundo grado; para la jurisprudencia, no hay falso juicio de existencia por omisión cuando la prueba es tenida en cuenta por el juez de primera instancia, y no por el juzgador ad quem ${ }^{24}$. Y es comprensible, porque de todas formas el juez que tiene el deber de examinar el acervo probatorio como un todo, es el de primera instancia, y si se advierte una omisión probatoria del tribunal, que puede ser comprensible por la limitación que se le traza a partir del recurso ordinario de apelación, no hay tal falso juicio de existencia si el juzgador a quo tuvo en cuenta la prueba y fijó su contenido, porque se entiende que en lo plenamente confirmado por el juez de segundo grado, hay una unidad jurídica inescindible con la sentencia de primera instancia ${ }^{25}$. Por ende, la preparación previa que se exige en la técnica casacional, implica el estudio serio de las dos sentencias, cuya unidad es el objeto de ataque del recurso.

La jurisprudencia ha señalado de forma reiterada la técnica correcta para plantear el error de hecho por falso juicio de existencia

de que le corresponde al juez "la formulación de inferencias lógicamente válidas", que puedan conducir a soluciones racionalmente justificadas, siendo entonces un "procedimiento verificable de manera intersubjetiva". Michele TARuffo, Consideraciones sobre prueba y motivación, en Nuevas tendencias del derecho probatorio, 41-56, 47 (Horacio Cruz-Tejada, ed., Universidad de los Andes, Bogotá, 2011). Así las cosas, motivar implica, aparte de la actividad jurídica de subsumir, la exteriorización de las razones de las premisas de hecho, lo cual facilita el control de la decisión judicial por parte de las instancias superiores si se hace uso de los recursos ordinarios y extraordinarios, como aclara SÁnCHEZ-VERA. JAVIER SÁNCHEZVera Gómez-Trelles, Variaciones sobre la presunción de inocencia. Análisis funcional desde el derecho penal, 117 (Marcial Pons, Madrid, 2012). Se trata de lo que explicitó en su momento JuAN IgARTUA-SALAVERRÍA como justificación interna (consistencia de la conclusión del silogismo con las premisas) y justificación externa (buenas razones para justificar las premisas). JuAn Igartua-SalaverRía, Valoración de la prueba, motivación y control en el proceso penal, 207 (Tirant lo Blanch, Valencia, 1995).

24 "De aquí que cuando en casación se ataca la sentencia de segundo grado se está impugnando, sin lugar a dudas, la de primera instancia en todo aquello que le es coincidente, pero, al mismo tiempo, esta cumple la función de suplir sus falencias y de cubrir sus silencios". Corte Suprema de Justicia, Sala Penal, 24 de septiembre de 1985, magistrado ponente Fabio Calderón-Botero.

25 "En el ámbito del recurso de casación impera recordar que en virtud del principio de unidad jurídica inescindible, los fallos de primera y segunda instancia forman un solo cuerpo en aquello que el ad quem imparta confirmación, motivo por el cual, para desvirtuar la presunción de acierto y legalidad en punto de constatar la motivación de tales decisiones, es ineludible verificar conjuntamente lo expuesto en ambas instancias, pues en no pocas ocasiones se complementan e incluso las falencias o vacíos de una son enmendadas o llenados por la otra, circunstancia que impone al recurrente encaminar su labor a derruir todos los fundamentos planteados, esto es, no únicamente los contenidos en la providencia de segundo grado, sino también los ofrecidos por el a quo". Corte Suprema de Justicia, Sala Penal, Proceso 37047, 26 de agosto de 2015, magistrado ponente Eugenio Fernández-Carlier. Disponible en: http://190.24.134.97/WebRelatoria/csj/index.xhtml 
por omisión. Cuando se omite apreciar una prueba materialmente obrante en el proceso, la demostración del yerro impone al casacionista el deber de identificar en el plenario o actuación la prueba omitida, objetivar su contenido en los aspectos sustanciales, analizar el mérito probatorio de conformidad con las reglas de la sana crítica y acreditar, mediante un análisis del conjunto probatorio y con la inclusión de la prueba omitida, que de no haberse presentado la omisión las conclusiones del fallo habrían sido distintas, lo cual determinaría una declaración de justicia diferente a la consignada en la sentencia impugnada ${ }^{26}$.

Es importante, de cara a la estricta observancia de esta metodología, que el casacionista se atenga rigurosamente al contenido de las pruebas no tenidas en cuenta por el juzgador, y que las valore de cara al principio que activa en definitiva la procedencia de la casación, como el de trascendencia ${ }^{27}$, explicando cómo las conclusiones del fallo hubieran variado sustancialmente si no se hubiera omitido la prueba, por lo que resulta evidente que este error de hecho debe tener la suficiente entidad como para desquiciar o enervar la sentencia. Sin lugar a dudas, esta exigencia de valoración de la prueba esencial omitida en relación con el conjunto probatorio, supone de forma perentoria tener en cuenta la fijación de los hechos y la valoración de los restantes medios de prueba obrantes en

26 Corte Suprema de Justicia, Sala Penal, Proceso 43033, 5 de marzo de 2014, magistrado ponente Fernando Alberto Castro-Caballero. Disponible en: http://190.24.134.97/WebRelatoria/ csj/index.xhtml. Corte Suprema de Justicia, Sala Penal, Proceso 32722, 16 de junio de 2010, magistrado ponente José Leonidas Bustos-Martínez. Disponible en: http://190.24.134.97/Web Relatoria/csj/index.xhtml. Corte Suprema de Justicia, Sala Penal, Proceso 27227, 21 de mayo de 2009, magistrado ponente Jorge Luis Quintero-Milanés. Disponible en: http://190.24.134.97/ WebRelatoria/csj/index.xhtml. Para el tratadista GeRMÁn PABÓN-Gómez, en relación con el error de hecho por falso juicio de existencia en la modalidad de ignoraciones probatorias, "deberá el casacionista de conformidad con el principio de trascendencia, y conforme al principio de apreciación de las pruebas en conjunto, demostrar, que de no haberse materializado las omisiones valorativas de prueba, las imputaciones fácticas y jurídicas falladas habrían sido en un todo, o en parte diferentes; confrontación y demostración trascendente, que en su desarrollo y sustentación, deberá igualmente respetar el haz probatorio existente material y jurídicamente; e integración de nuevos ejercicios valorativos de conjunto, con los que se harán las debidas infirmaciones o verificaciones, acerca de si lo sustancialmente fallado, sufre afectaciones o mutaciones de exclusiones de autorías, de exclusiones de injusto, de atenuación de pena, o de proyecciones constructivas de in dubio pro reo". Germán PABón-Gómez, De la casación y la revisión penal en el Estado constitucional, social y democrático de derecho, 247-248 (Ediciones Doctrina y Ley, Bogotá, 2003).

27 Si el yerro influye en la decisión "total o parcialmente produciendo su alteración, es trascendente; si no incide nada del fallo, es decir, si no hace que este sea modificado, es intrascendente". Álvaro Orlando Pérez-Pinzón, Introducción al estudio de la casación penal, 158 (Temis, Bogotá, 2014). 
el expediente, sin ensayar posturas personales sobre tales medios ignorando la realidad procesal ${ }^{28}$. Por lo demás, el esfuerzo del casacionista por valorar la prueba omitida no puede llevarlo a su distorsión, o al ensayo de opiniones que no se compadecen con el tenor literal de la misma.

\section{B. El error de hecho por falso juicio de identidad}

El error de hecho por falso juicio de identidad acontece cuando los sentenciadores al ponderar el medio probatorio distorsionan su contenido cercenándolo, adicionándolo o tergiversándolo, por lo que en tal caso corresponde al demandante identificar, mediante el cotejo objetivo de lo dicho en el elemento de convicción y lo asumido en el fallo, el aparte omitido o añadido a la prueba, los efectos producidos a partir de ello y, lo más importante, cuál es la trascendencia de la falencia en la parte resolutiva de la sentencia atacada. El error en este caso es de apreciación, ya que el sentenciador acierta en la selección de la prueba invocada, pero le otorga un sentido y un alcance equivocados, contrarios a la verdadera esencia en ella contenida; en otras palabras, se hace decir a la prueba algo contrario a su espíritu ${ }^{29}$, por lo que el equívoco judicial tiene qué ver, en últimas, con las alteraciones que el sentenciador ejerza sobre el contenido de la prueba. Puede ser, en definitiva, en este error de hecho, que se le haga decir a la prueba "más de lo que su texto reza, menos de lo que su contenido encierra, o algo totalmente distinto de aquello que en realidad expresa" ${ }^{30}$.

28 "También es del caso recordar, que en desarrollo de este tipo de reparos, como en los demás, no está permitido ensayar posturas personales acerca de la valoración de los elementos de convicción, pues un proceder de ese talante desconoce la naturaleza extraordinaria del recurso de casación. Es evidente entonces, que la tarea argumentativa puesta de manifiesto no fue cumplida por el defensor, pero además, es claro que en su interés por hacer prevalecer su opinión personal, ignora la realidad procesal". Corte Suprema de Justicia, Sala Penal, Proceso 38571, 16 de mayo de 2012, magistrado ponente Fernando Alberto Castro-Caballero. Disponible en: http://190.24.134.97/WebRelatoria/csj/index.xhtml

29 Corte Suprema de Justicia, Sala Penal, Proceso 19052, 9 de julio de 1985, magistrado ponente Hernando Baquero-Borda. Para Hernando Morales-Molina, en estos casos, el error se presenta cuando la prueba "al ser analizada en sí misma y no en función de su mérito probatorio, se la interpreta sin fidelidad objetiva para desconocerle su propia sustancia, o para restringirle o ampliarle o cambiarle su contenido real, vale decir, cuando se la desvirtúa en su contenido literal, se le varía este". Hernando Morales-Molina, Técnica de casación civil, 212 (Lerner, Bogotá, 1963).

30 Corte Suprema de Justicia, Sala Penal, Proceso 10115, 7 de octubre de 1997, magistrado ponente Fernando Enrique Arboleda-Ripoll. Disponible en: http://190.24.134.97/WebRelatoria/ csj/index.xhtml 
La consecuencia natural de proceder a tomar una parte de la prueba por el todo (esto es, la acción de cercenar), o a fundar el todo probatorio en una de sus partes, es la tergiversación de la sustancia de la prueba; por eso, cuando el sentenciador toma en cuenta solamente una parte de la prueba, desconociendo el resto de la misma ${ }^{31}$, y considera su contenido esencial como expresado exclusivamente por esa parte valorada, incurre no en falso juicio de existencia, sino en falso juicio de identidad, ya que no existen en casación falsos juicios de existencia parciales ${ }^{32}$.

El error de hecho se presenta fundamentalmente en tres modalidades, en razón a que al aprehender el contenido de la prueba, el juzgador le resta circunstancias trascendentes (es decir, omite aspectos importantes de ella), o le agrega aspectos ajenos a su texto, o simplemente desfigura su estricto sentido literal ${ }^{33}$. La metodología a plantear para este yerro probatorio en la demanda debe ser muy exigente, esto con miras a evitar que en la censura el casacionista termine formulando su propia opinión personal sobre el contenido de la prueba afectada de falso juicio de identidad, ya que esta posibilidad de entrada contradice la doctrina inveterada de la Corte, en el sentido de que la casación no es una tercera instancia en la cual se puede cuestionar libremente el fallo y la valoración de las pruebas, planteando simples discrepancias sobre su mérito

31 En este punto, para entender simplemente la naturaleza de este yerro, podríamos acudir a la explicación que ClaUde-AdRIEN HelvéTIUS brinda sobre la ignorancia: "Nos equivocamos cuando, arrastrados por una pasión, y fijando toda nuestra atención en uno de los lados de un objeto, queremos juzgar el objeto entero según ese único aspecto". Claude-Adrien Helvétius, Del espiritu, 20 (Laetoli, Pamplona, 2012).

32 "Si los juzgadores, como lo afirma el casacionista, omitieron tener en cuenta este aspecto del testimonio, pero lo apreciaron en lo demás, el error cometido no sería de existencia, sino eventualmente de identidad, que se presenta cuando el operador judicial aprecia la prueba, pero al hacerlo omite tener en cuenta afirmaciones o negaciones que contiene, o le atribuye afirmaciones o negaciones que no incluye, o de cualquier manera altera su literalidad, haciendo que diga lo que materialmente no expresa". Yesid Ramírez-BASTIDAS, Casación penal, 572 (Leyer, Bogotá, 2011).

33 "Cuando se alega al amparo de la causal primera de casación un error de hecho por falso juicio de identidad en la apreciación de la prueba, lo que se pretende expresar es que el Tribunal, al emitir el fallo que se impugna en sede de este extraordinario recurso, distorsionó o tergiversó el contenido fáctico de determinado medio probatorio, haciéndole decir lo que en realidad no dice, bien sea porque realizó una lectura equivocada de su texto, o bien porque le agregó aspectos que no contiene, o bien porque omitió tener en cuenta partes importantes del mismo". Corte Suprema de Justicia, Sala Penal, Proceso 21977, 1 de julio de 2009, magistrado ponente Julio Enrique Socha-Salamanca. Disponible en: http:/190.24.134.97/WebRelatoria/csj/index. xhtml 
suasorio $^{34}$. Por ende, en una posición jurisprudencial valiosa por su talante pedagógico, la Sala Penal de la Corte afirmó que en la formulación del falso juicio de identidad,

Se trata, como lo tiene dicho la jurisprudencia de la Corte, de realizar un elemental ejercicio de confrontación que, a la manera de una doble columna, reproduzca en la primera lo que textualmente dijo la prueba y en la segunda lo que se le hizo decir, para destacar luego la incidencia del yerro en la decisión, de forma que si no se hubiera cometido el error, el sentido del fallo habría sido otro sustancialmente diferente ${ }^{35}$.

Cuando se plantea el error de hecho por falso juicio de identidad, es importante delimitar de forma clara lo que el juzgador le hizo decir a la prueba, y lo que en realidad dice la prueba, todo con el fin de inferir claramente cuál fue aquel contenido de la prueba ignorado, adicionado o tergiversado, ateniéndose siempre el casacionista al hecho genuino que se deriva de la prueba contemplada como un todo.

Para los falsos juicios de existencia y de identidad, el éxito del cargo se sustenta en la idea de la incidencia del yerro en la parte resolutiva del fallo, porque bien puede ocurrir que el sentenciador incurra en los errores de valoración probatoria que invoca el casacionista; pero el esfuerzo jurídico de este será en vano si no logra acreditar que esos errores tienen la virtualidad de variar el sentido del fallo, para valorar las pruebas omitidas o tergiversadas en su contenido, en conjunto con las restantes pruebas valoradas por las instancias, siendo este el complejo ejercicio valorativo que debe llevar a cabo el casacionista para asegurar un planteamiento correcto de la censura y su consecuente éxito ${ }^{36}$. Pero, se insiste, este ejercicio

34 Corte Suprema de Justicia, Sala Penal, Proceso 25971, 28 de septiembre de 2006, magistrada ponente Marina Pulido de Barón. Disponible en: http://190.24.134.97/WebRelatoria/csj/index. xhtml

35 Corte Suprema de Justicia, Sala Penal, Proceso 23772, 3 de agosto de 2005, magistrado ponente Álvaro Orlando Pérez-Pinzón. Disponible en: http://190.24.134.97/WebRelatoria/csj/index. xhtml

36 "En todo caso de acudir a la violación indirecta de la ley, compete al actor precisar la naturaleza del error, el sentido de la violación y, luego de identificar el desacierto, demostrar su incidencia en la parte resolutiva del fallo acusado, en proceso de demostración completo, esto es, acreditando cómo de corregirse el yerro sobre las pruebas erradamente apreciadas y valorárselas adecuadamente junto con las restantes válidamente incorporadas al proceso sobre las que no concurre desacierto alguno en su apreciación, la sentencia habría sido de distinto contenido". Corte Suprema de Justicia, Sala Penal, Proceso 12601, 18 de julio de 2000, magistrado ponente Fernando Enrique Arboleda-Ripoll. Disponible en: http://190.24.134.97/ 
debe realizarse siempre con estricto apego al contenido sustancial que se desprende de las pruebas valoradas por el juzgador, y con fiel sujeción al contenido que se deriva de la prueba marginada o malinterpretada por adiciones, cercenamientos o tergiversaciones.

Es realmente escandaloso el número de demandas inadmitidas por el famoso argumento de la opinión personal del casacionista. En este punto, con miras a preservar la tutela judicial efectiva y evitar eventuales injusticias, el esfuerzo jurisprudencial debería encaminarse a un refuerzo de la actividad pedagógica sobre el planteamiento de las diversas causales, en un lenguaje claro y sencillo, que promueva el entendimiento simple de la metodología del recurso, y de paso contribuya a la desformalización paulatina de las complejas exigencias jurisprudenciales ${ }^{37}$. La sentencia de 3 de agosto de 2005 ya citada es un excelente ejemplo de transmisión didáctica del conocimiento sobre la técnica de fijación del falso juicio de identidad, que hace gala de simplicidad mas no de brumosidad.

Para coadyuvar a este ideal de claridad, se propone el siguiente ejercicio: el casacionista debería recordar la sugerencia de NICOLA Framarino dei Malatesta en relación con lo que él denomina el carácter natural y social del convencimiento del juez. El convencimiento, como máximo grado de persuasión, debe ser no solamente natural - es decir, dimanante únicamente de la acción genuina de las pruebas - y no artificial, esto es, producido por razones

\footnotetext{
WebRelatoria/csj/index.xhtml. Hernando Morales-Molina en su clásico manual de casación civil, citando jurisprudencia de la Corte y el inciso 2 del numeral 1 del artículo 520 del derogado Código Judicial [Ley 105 de 1931, derogada por el artículo 698 del Decreto 1400 de 1970], advertía que el error en este recurso extraordinario debía ser evidente, claro, patente, manifiesto, grave, incidente de tal forma que si no hubiera sido por el error, la sentencia habría tenido un contenido distinto, y de tal magnitud que permitiera ver que la apreciación probatoria pugna evidentemente y de manera notoria con la realidad del proceso, sin mayor análisis y esforzados razonamientos. Hernando Morales-Molina, Técnica de casación civil, 216 (Lerner, Bogotá, 1963). Colombia, Ley 105 de 1931, Código Judicial, sobre organización judicial y procedimiento civil, 21.823 Diario Oficial, 24 de octubre de 1931. Disponible en: http://www.icbf.gov.co/cargues/avance/docs/ley_0105_1931.htm

$37 \mathrm{Al}$ respecto, ver la acertada crítica de Gustavo Moreno-Rivera en un reciente ensayo: "Se exige que al interior del proceso la casación sea eficaz y logre garantizar una tutela judicial efectiva. Lo que no sucede cuando se convierte en una forma institucionalizada de denegar justicia y los interesados deben acudir a la 'acción de tutela', porque ha sido desestimado el estudio del recurso aduciendo simples formalismos, mala elaboración o defectos de técnica. Motivo por el cual, consideramos que la casación debe ser de fácil acceso y elaboración, buscando con ello evitar un decisionismo caracterizado por la negación institucionalizada del acceso a la justicia, que sobra decir, elude los preceptos constitucionales vigentes". LuIs Gustavo Moreno-Rivera, La casación en la ley 906 de 2004. Teoría y práctica bajo la nueva orientación constitucional, 214 (Ediciones Nueva Jurídica, Bogotá, 2013).
} 
extrañas a su naturaleza intrínseca; sino que también debe ser tal que si los hechos y las pruebas sometidos a su conocimiento son propuestos al juicio desinteresado de cualquier otro ciudadano racional, deberían producir en este también la misma convicción que produjeron en el juzgador ${ }^{38}$. Estos predicados tan anhelados por Nicola Framarino dei MALATESTA para el convencimiento en la actividad judicial, debería tenerlos en cuenta el casacionista en el momento de emprender el análisis de incidencia del yerro in iudicando sobre la prueba, porque en este escenario crucial de la técnica de casación a él le corresponde asignarle expresamente un contenido a la prueba omitida que se derive de su propia naturaleza, y que sea meridianamente perceptible por cualquier otro ciudadano, esto con el fin de tratar de evitar o minimizar el riesgo, probablemente presente en estos casos, de una valoración arbitraria, parcializada y quizás muy apasionada que distorsione los contornos objetivos de la prueba, observación esta que resulta igualmente aplicable para el análisis de la prueba considerada por el juez pero tergiversada en su contenido esencial. Aquí debe extremarse una valoración que indique certeza natural y social.

Esa valoración en conjunto con los restantes medios de prueba, constantemente recordada por la jurisprudencia de la Sala de Casación Penal, no puede ser descuidada por el actor, ya que los falsos juicios de existencia o de identidad identificados podrían no tener el suficiente peso para modificar las conclusiones del fallo, al no enervar sustancialmente las inferencias del sentenciador originadas en las pruebas obrantes en el proceso que no fueron objeto de los errores de hecho. Por esta razón, la noción de error tanto en los falsos juicios de existencia como en los falsos juicios de identidad implica el análisis de dos momentos: no solamente se trata de constatar el yerro inicial de desconsideración o tergiversación de la prueba, ya que la exigencia de trascendencia implica adicionalmente el análisis de la incidencia del error en la parte resolutiva de la sentencia, cuestión que se dilucida verificando que, de no haber incurrido en el mismo, las conclusiones de la sentencia habrían sido diferentes.

38 Nicola Framarino dei Malatesta, Lógica de las pruebas en materia criminal, Tomo I, 53-56 (Temis, Bogotá, 2002). 
En cuanto a los cambios que se hubieran podido advertir de no haber incurrido el tribunal en los yerros fácticos de apreciación, podrían mencionarse aquellos referentes a exclusiones de las categorías de tipicidad, antijuridicidad o culpabilidad. También se deben mencionar las modificaciones favorables en relación con: a) la forma de intervención en el injusto (por ejemplo, la degradación de coautor a cómplice) o con el tipo penal que se aplicó, b) las atenuantes genéricas o específicas, c) la dosificación judicial de la pena y d) la conclusión de absolución por aplicación del in dubio pro reo. En este último caso, la trascendencia del error se identifica cuando de las pruebas indebidamente valoradas por errores de omisión o de tergiversación, surgen motivos divergentes de la afirmación de responsabilidad penal dignos de ser tenidos en cuenta ${ }^{39}$, que no permiten afirmar una condena, bajo el supuesto de que esta exige no solamente que la probabilidad de la hipótesis de la acusación supere la probabilidad de la hipótesis de la defensa ${ }^{40}$, sino además que debe necesariamente excluir una duda esencial respecto a la inocencia ${ }^{41}$.

Por último, es importante no olvidar que la violación indirecta implica, en la formulación idónea del cargo, identificar finalmente las violaciones medio en relación con las pruebas, equívocos conducentes a las violaciones fin de la ley sustancial en los sentidos de "falta de aplicación" o de "aplicación indebida"42. En otras palabras,

39 Siguiendo el planteamiento de Nicola Framarino dei Malatesta, se habla de certeza cuando los motivos divergentes de la afirmación no merecen ser racionalmente considerados, y la afirmación o tesis se mantiene, mientras que en la duda hay una equiparación de los motivos convergentes y divergentes; en la probabilidad, hay menores motivos que apartan de la creencia, dignos de ser tenidos en cuenta, y mayores motivos que convergen hacia la creencia. Hay credibilidad cuando todos los motivos son unívocamente convergentes. En la certeza "no hay motivos serios que aparten de la creencia". Nicola Framarino dei Malatesta, Lógica de las pruebas en materia criminal, Tomo I, 73 (Temis, Bogotá, 2002).

40 "Teniendo en cuenta la presunción de inocencia, el sistema acusatorio y otros presupuestos del modelo garantista, para que haya condena es necesario que la probabilidad de la hipótesis de la acusación supere la probabilidad de la hipótesis de la defensa". PAOLo ComanduCCI, Razonamiento jurídico. Elementos para un modelo, 111 (Fontamara, México, 2004).

41 José Luis Castillo-Alva, La motivación de la valoración de la prueba en materia penal, 97 (Grijley \& Estudio Penal Castillo Alva \& Abogados, Lima, 2013). Concluye este autor, citando al tratadista español JuAn IgARTUA-SALAVERría, que "para desvirtuar la presunción de inocencia, no es bastante que la hipótesis acusatoria alcance un grado de probabilidad simplemente superior al de la defensa; la superioridad ha de alcanzar una magnitud aplastante, por exigencias del guion garantista”. José LuIs CASTILlo-Alva, La motivación de la valoración de la prueba en materia penal, 97 (Grijley \& Estudio Penal Castillo Alva \& Abogados, Lima, 2013).

42 En la aplicación indebida, como modalidad de la violación directa de la ley sustancial, el error 
el casacionista debe concretar las normas medio que fueron infringidas por el sentenciador (que, como es lógico, terminan siendo aquellas que recogen los principios de unidad de la prueba, necesidad y método de la sana crítica) ante la ocurrencia de los errores de hecho, y demostrar que tales equívocos generaron, en el marco mismo de la aplicación de la ley sustancial, la aplicación indebida de normas jurídico-penales (por ejemplo, aquellas relacionadas con el tipo penal, con las formas de intervención en el delito, con la antijuridicidad, la culpabilidad, el tipo subjetivo o con el estándar de certeza que se exige para condenar ${ }^{43}$, etc.) y la consecuente falta de aplicación de las que estaban llamadas legalmente a regular el caso concreto ${ }^{44}$, como puede ser las que consagran la presunción de

in iudicando se manifiesta en la falsa adecuación de los hechos probados a los supuestos que contempla la norma, es decir, "cuando el juzgador se equivoca en el proceso de subsunción de los hechos en el derecho, o cuando, habiendo acertado en ese proceso de adecuación típica, termina aplicando una norma distinta de la inicialmente seleccionada". Corte Suprema de Justicia, Sala Penal, Proceso 12658, 18 de abril de 2002, magistrado ponente Jorge Aníbal Gómez-Gallego. Disponible en: http://190.24.134.97/WebRelatoria/csj/index.xhtml. En la falta de aplicación o exclusión evidente, "el juez yerra acerca de la existencia de la norma y por eso no la aplica al caso específico que la reclama. Ignora o desconoce la ley que regula la materia y no la tiene en cuenta, debido a que ha incurrido en error sobre su existencia o validez en el tiempo o el espacio". Corte Suprema de Justicia, Sala Penal, Proceso 19970, 27 de abril de 2005, magistrado ponente Édgar Lombana-Trujillo. Disponible en: http://190.24.134.97/WebRelatoria/csj/index.xhtml

43 La jurisprudencia penal de la Corte ha establecido que si se invoca la violación indirecta del precepto que consagra el in dubio pro reo, por haberse incurrido en errores de hecho o de derecho en la apreciación probatoria, "además del señalamiento concreto de la especie de error probatorio, el casacionista debe demostrar que el fallador llegó a la errada conclusión de que las pruebas no conducen a la certeza del hecho o la responsabilidad del procesado (aplicación indebida), o erradamente concluye que los medios dan la certeza requerida y condena, cuando en verdad de ellos surge incertidumbre que debió ser resuelta a favor del procesado (falta de aplicación)". Corte Suprema de Justicia, Sala Penal, Proceso 14961, 7 de septiembre de 2000, magistrado ponente Fernando Enrique Arboleda-Ripoll. Disponible en: http://190.24.134.97/ WebRelatoria/csj/index.xhtml

44 Esta exigencia se entiende solo si se tiene en cuenta que "la indebida aplicación por lo general y de manera complementaria apareja una violación de la ley sustancial en sentido de falta de aplicación de la debida norma correspondiente a los hechos. Por tanto, si al efectuarse una indebida aplicación se involucra la falta de aplicación de otra norma, se torna necesario que el casacionista en la censura integre estos extremos, pues de no hacerlo la Corte por virtud del principio de limitación no podrá pronunciarse a efectos de la sentencia de reemplazo". Germán Pabón-Gómez, De la casación en el sistema acusatorio, 193 (Grupo Editorial Ibáñez, Universidad de los Andes, Bogotá, 2011). Esta precisión es importante con miras a consolidar la debida sustentación del cargo postulando la proposición jurídica completa, tesis de antaño en la Sala de Casación Penal: "Ha dicho reiteradamente la Corte que cuando se alega violación directa de la ley por aplicación indebida de una norma, está obligado el recurrente no solo a determinar la que fue indebidamente aplicada, sino también la que en su lugar debe aplicarse, dando en cada caso las razones pertinentes, pues debiendo la Corte dictar la sentencia sustitutiva en caso de que el recurso prospere, estaría imposibilitada para ello si esta no se determina". Corte Suprema de Justicia, Sala Penal, Proceso 1118, 17 de junio de 1987, magistrado ponente Jaime Giraldo-Ángel. Corte Suprema de Justicia, Sala Penal, Proceso 367, 10 de febrero de 1987, magistrado ponente Guillermo Duque-Ruiz. 
inocencia y el in dubio pro reo ${ }^{45}$, y la normatividad relacionada con las categorías del delito (tipicidad, antijuridicidad y culpabilidad) que, según el caso, debió ser aplicada.

Por ejemplo, si el sentenciador incurrió en falsos juicios de identidad y en falsos juicios de existencia cuya trascendencia implica la ausencia de responsabilidad penal del procesado en los hechos que fueron adecuados en el delito de homicidio, se debe determinar que la violación de las normas medio que fijan la manera de apreciar las pruebas condujeron a la violación de las normas fin sustanciales por aplicación indebida del tipo penal (artículo 103, Constitución Política ${ }^{46}$ ), y a la falta de aplicación de las normas que regulan los principios de presunción de inocencia, in dubio pro reo, tipicidad (en el sentido de que el comportamiento, por ejemplo, fue atípico por haberse configurado un error invencible o un riesgo jurídicamente permitido en aplicación de la teoría de la imputación objetiva, etc.), antijuridicidad (por ejemplo, porque el error in iudicando permitió la inaplicación de un estado de necesidad justificante o una legítima defensa) o culpabilidad (porque el error de hecho no permitió reconocer un error de prohibición invencible, etc.), según las circunstancias del proceso.

En estricto sentido, la presentación metódica y clara de estas aplicaciones indebidas y consecuentes faltas de aplicación es obligatoria para fijar la violación de la ley, e incluso así el actor fracase en el cargo de su libelo, contribuye a afirmar o a replantear aspectos

45 Artículo 7. Presunción de inocencia. Toda persona se presume inocente y debe ser tratada como tal mientras no se produzca una sentencia condenatoria definitiva sobre su responsabilidad penal. En las actuaciones penales toda duda debe resolverse en favor del procesado. Únicamente las condenas proferidas en sentencias judiciales en firme tienen la calidad de antecedentes penales y contravencionales. Colombia, Ley 600 de 2000, por la cual se expide el Código de Procedimiento Penal, 44.097 Diario Oficial, 24 de julio de 2000. Disponible en: http://www.secretariasenado.gov.co/senado/basedoc/ley_0600_2000_pr004.html

Artículo 7. Presunción de inocencia e in dubio pro reo. Toda persona se presume inocente y debe ser tratada como tal, mientras no quede en firme decisión judicial definitiva sobre su responsabilidad penal. En consecuencia, corresponderá al órgano de persecución penal la carga de la prueba acerca de la responsabilidad penal. La duda que se presente se resolverá a favor del procesado. En ningún caso podrá invertirse esta carga probatoria. Para proferir sentencia condenatoria deberá existir convencimiento de la responsabilidad penal del acusado, más allá de toda duda. Colombia, Ley 906 de 2004, por la cual se expide el Código de Procedimiento Penal, 45.657 Diario Oficial, 31 de agosto de 2004. Disponible en: http://www. secretariasenado.gov.co/senado/basedoc/ley_0906_2004.html

46 Colombia, Constitución Política, versión corregida 116 Gaceta Constitucional, 20 de julio de 1991. Disponible en: http://www.secretariasenado.gov.co/senado/basedoc/constitucion_politica_1991.html 
fundamentales de la interpretación de las normas jurídicas de la parte general del Código Penal ${ }^{47}$ y permite la inserción de discusiones dogmáticas fundamentales para la solución de los casos, cuestiones relevantes si en verdad, como debe ser, se quiere concebir la teoría del delito como instrumento de aplicación racional, previsible e igualitaria de la ley penal ${ }^{48}$.

Hay que decir que frente a la necesaria sustentación de las categorías del delito aplicadas indebidamente y dejadas de aplicar, hay un descuido frecuente por parte de los mismos demandantes, quienes omiten esta referencia, y por parte de la Sala Penal de la Corte, que a su turno ha dejado de aprovechar las sentencias de casación para unificar la jurisprudencia en puntos clave de la teoría general del delito ${ }^{49}$, olvidada en estos últimos tiempos por una inadmisible concentración en la mera técnica del recurso y en los aspectos procesales.

\section{El error de hecho por falso raciocinio}

\section{Esta modalidad de error de hecho, de origen nacional ${ }^{50}$, supone necesariamente que la prueba es tenida en cuenta por las instan-}

47 Colombia, Ley 599 de 2000, por la cual se expide el Código Penal, 44.097 Diario Oficial, 24 de julio de 2000. Disponible en: http://www.secretariasenado.gov.co/senado/basedoc/ ley_0599_2000.html

48 La dogmática jurídico-penal, enseña Enrique Gimbernat-OrdeIG, "al señalar límites y definir conceptos", hace posible "una aplicación segura y calculable del derecho penal, hace posible sustraerle a la irracionalidad, a la arbitrariedad y a la improvisación”. ENRIQUE GIMBERNATOrdeIG, Estudios de derecho penal, 158 (Tecnos, Madrid, 1990).

49 Como señala Fernando Velásquez-Velásquez, quien con acierto se lamenta del olvido de la dogmática penal patente en la jurisprudencia de la Corte y concluye que "el recurso extraordinario de casación no parece ser ya la sede destinada a librar importantes debates de tipo técnico-jurídico, unificar la jurisprudencia y enderezar entuertos, sino la oportunidad para redactar alegatos que defienden las decisiones de los inferiores". Fernando VelásQuezVelÁSQUez \& Christian WolfFHüGEL-GutiérRez, La diferencia entre el dolo eventual y la culpa consciente en la reciente jurisprudencia, 6 Cuadernos de Derecho Penal, 99-181, 165 (2011). Disponible en: http://revistas.usergioarboleda.edu.co/index.php/cuadernos_de_derecho_penal/ article/viewFile/395/342

50 'El nombre 'falso raciocinio', como categoría autónoma dentro del error de hecho, es de origen nacional. En Colombia, más o menos hasta 1998, se hablaba solamente de dos clases de error de hecho: falso juicio de existencia y falso juicio de identidad, y dentro de este último se incluía el 'falso raciocinio', sin ese nombre. Cuando se infringía la sana crítica se aludía generalmente a 'error de hecho por falsa apreciación'. El 'falso raciocinio' entonces, carecía de independencia, que toma solamente a partir de esos días, a diferencia de la legislación foránea, que, habitualmente, mantiene los errores de raciocinio dentro del falso juicio de identidad". Álvaro Orlando Pérez-Pinzón, Introducción al estudio de la casación penal, 178 (Temis, Bogotá, 2014). 
cias y valorada en su contenido sin ninguna clase de desfiguración o distorsión, pero al momento de asignar el mérito probatorio a la misma, se desconocen en ese ejercicio valorativo las reglas de la sana crítica $^{51}$, esto es, las reglas de la lógica, las máximas de la experiencia ${ }^{52}$ y los principios de la ciencia. Se trata de la causal más exigente en materia de casación, porque el objetivo que se busca al plantear un cargo de esta naturaleza es el señalamiento de un yerro en el razonamiento del juzgador que debe ser relevante y ostensible, dado por un desconocimiento grosero de las reglas de la sana crítica. Este énfasis es muy importante, porque es la única manera en que puede ser viable la formulación de este error, amén de su exigencia de trascendencia, teniendo en cuenta la valoración del restante acervo probatorio.

51 Sus antecedentes históricos se pueden rastrear en la filosofía griega y en el derecho romano, pero su consagración legislativa se dio a partir de la Ley de Enjuiciamiento Civil Española de 1855, en cuyo artículo 317 se dijo que "los jueces y tribunales apreciarán según las reglas de la sana crítica, la fuerza probatoria de las declaraciones de los testigos". España, Ley de Enjuiciamiento Civil (Imprenta del Ministerio de Gracia y Justicia, Madrid, 1855). Edición digital de la Universidad de Sevilla. Disponible en: http://fama2.us.es/fde/ocr/2006/leyDe EnjuiciamientoCivil1855.pdf. Según Gustavo Cuello-Iriarte, "en España debía nacer la sana crítica, porque fue ella la depositaria por siglos de las culturas y principios jurídicos de la Grecia y la Roma clásicas; a ella le tocó sufrir la influencia del primitivo derecho germánico, de los principios culturales de la civilización islámica; y fue ella la precursora del retorno a la civilización. Por ello, con Santiago Sentís-Melendo, decimos que es evidente, 'ya sea como concepto o meramente como expresión', que la sana crítica pertenece de manera exclusiva a nuestro mundo procesal: es una creación hispana que en España y en América se desarrolla". Gustavo Cuello-Iriarte, La sana crítica, sistema de valoración de la prueba judicial, 236 (Pontificia Universidad Javeriana, Bogotá, 2007). Incluso puede rastrearse en la obra capital de CESARE BeCCARIA una breve alusión a la libre apreciación de la prueba apelando al "buen sentido" innato de los seres humanos, esto como crítica vehemente al modo de valorar en el derecho del antiguo régimen: "Dove le leggi siano chiare e precise l'officio di un giudice non consiste in altro che di accertare un fatto. Se nel cercare le prove di un delitto richiedesi abilità e destrezza, se nel presentarne il risultato è necessario chiarezza e precisione, per giudicarne dal risultato medesimo non vi si richiede che un semplice ed ordinario buon senso, meno fallace che il sapere di un giudice assuefatto a voler trovar rei, e che tutto riduce ad un sistema fattizio imprestato da' suoi istudi”. Cesare BeCCARIa, Dei delitti e delle pene, Capitolo 14, Indizi, e forme di giudizi, 28 (Stamperia di Pietro Bizzoni successo a Bolzani, Pavia, 1817). Edición digital disponible en: http://bepi1949.altervista.org/delitti/index.html, http://bepi1949. altervista.org/delitti/Cap14.htm

52 "Las reglas de la experiencia son construcciones teóricas, argüidas por el intérprete de la norma, que guardan relación con las costumbres, cultura y cotidiano vivir de grupos humanos en un contexto específico dado. Como son asimilables a leyes científicas, tienen pretensiones de carácter universal (aunque serían más equivalentes a enunciados de alta probabilidad), razón por la cual deben ajustarse a la fórmula lógica siempre o casi siempre que ocurre A, entonces sucede B". Corte Suprema de Justicia, Sala Penal, Proceso 36824, 12 de septiembre de 2012, magistrado ponente Julio Socha-Salamanca. Disponible en: http://190.24.134.101/ corte/wp-content/uploads/relatorias/pe/bloct2012/36824(12-09-12).doc 
La Sala Penal ha puntualizado que cuando se predica un error de hecho en el sentido de falso raciocinio, se debe demostrar que el ejercicio valorativo del juzgador desconoció los postulados de la lógica, las leyes de la ciencia o las reglas de la experiencia, es decir, de los principios de la sana crítica como método de apreciación probatoria. Empero, para el cumplimiento de esta carga, el demandante en casación está obligado a señalar el medio de prueba sobre el que recae el error, identificar aquello que expresamente dice y se deduce de él, el mérito persuasivo otorgado al mismo por el sentenciador, desarrollar con precisión la regla lógica, la ley científica o la máxima de la experiencia aplicada erradamente al realizar el proceso de valoración de las pruebas, así como la que debió de servir de apoyo, la norma de derecho sustancial indirectamente excluida o indebidamente aplicada o interpretada y al final demostrar que, de no haberse incurrido en el yerro, el sentido de la sentencia habría sido sustancialmente opuesto ${ }^{53}$.

La sana crítica como método de valoración supone que la apreciación debe ser razonada, crítica, sustentada en las "reglas del correcto entendimiento humano" 54 . De igual manera, el resultado de esa apreciación crítica debe ser explicado en un fallo motivado, lo cual puede armonizarse con el requisito insoslayable que deben tener los autos y las sentencias respecto a fundamentación fáctica, probatoria y jurídica con indicación de los motivos de estimación y desestimación de las pruebas admitidas en el juicio oral, según el artículo 162 de la Ley 906 de 2004.

El falso raciocinio en la demanda de casación supone un ataque frontal al razonamiento falso plasmado de forma evidente en la sentencia. Por esta razón, las censuras que invocan un falso raciocinio pero controvierten en exclusiva la manera razonada en que el tribunal finalmente llega a sus conclusiones imponiendo puntos

53 Corte Suprema de Justicia, Sala Penal, Proceso 44639, 19 de agosto de 2015, magistrado ponente Eyder Patiño-Cabrera. Disponible en: http://190.24.134.97/WebRelatoria/csj/index. xhtml

54 "En ellas interfieren las reglas de la lógica y las reglas de la experiencia del juez. Por ende, se dice que el juez no es libre de razonar a voluntad, discrecionalmente, arbitrariamente. Esta manera de actuar no sería sana crítica, sino libre convicción. La sana crítica es la unión de la lógica y la experiencia, sin excesivas abstracciones de orden intelectual, pero también sin olvidar esos preceptos que los filósofos llaman higiene mental tendientes a asegurar el más certero y eficaz razonamiento". Eduardo Juan Couture, Fundamentos del derecho procesal civil, 270 y 271 (Depalma, Buenos Aires, 1962). 
de vista subjetivos sobre la forma en que debió valorarse la prueba, están destinadas a la desestimación, porque se trata de la fijación de un error relevante y posterior demostración de su trascendencia, y no de la mera confrontación o discusión sobre la particular manera en que se llevó a cabo el ejercicio valorativo, posibilidad que de entrada supondría la generación de un nuevo debate de instancia improcedente según el objeto de la casación ${ }^{55}$; además, y en correspondencia con la denominada doble presunción de acierto y legalidad que cobija a las sentencias de segundo grado, siempre el razonamiento del tribunal tendrá prevalencia, salvo que, desde luego, se demuestre de forma contundente un desconocimiento ostensible de las reglas de la sana crítica.

En este orden de ideas, un aire de pesimismo suele rondar con el solo hecho de pensar en abordar esta causal, y no es para menos: su dificultad es ostensible porque la confrontación con el razonamiento del sentenciador debe necesariamente pasar por el tamiz de un error protuberante en cuanto al uso de las reglas de la sana crítica $^{56}$, y no con una simple afrenta argumentativa sobre la valoración probatoria que desea el casacionista, que puede incluso ser impecable, pero que en casación no tiene una preponderancia mayor que la valoración argumentativa del juzgador ad quem. Por lo tanto, será preferible estudiar acuciosamente la eventual existencia, en el fallo a censurar, de falsos juicios de existencia o falsos juicios de identidad antes de aventurarse en la causal más compleja de la casación penal.

55 "La finalidad del recurso de casación es derruir la doble presunción de acierto y legalidad de la sentencia objetada; por tanto, quien aspira a un pronunciamiento de fondo debe elaborar una demanda que cumpla con determinadas exigencias, de tal manera que la formulación y desarrollo de los cargos se ciña al imperativo de claridad y precisión, en el marco de argumentación inherente a cada una de las causales taxativamente consagradas en el ordenamiento jurídico. Con ese propósito, el interesado está en el deber de acreditar la ocurrencia de incuestionables errores judiciales y su repercusión en el sentido y/o alcance del fallo objeto de censura. No se trata de un mecanismo de libre configuración, desprovisto de todo rigor, que habilite un espacio para alegar como en las instancias y prolongar un debate sobre aquellos aspectos ya controvertidos por los sujetos procesales y definidos por el juzgador". Corte Suprema de Justicia, Sala Penal, Proceso 40431, 24 de abril de 2013, magistrado ponente José Luis Barceló-Camacho. Disponible en: http://190.24.134.97/WebRelatoria/csj/index.xhtml

56 Proceder complejo, que requiere una formación sólida en filosofía, lógica y argumentación jurídica, además del estudio previo de las metodologías, de por sí bastante meticulosas, que ha establecido la Sala Penal de la Corte en su jurisprudencia para plantear el cargo, dependiendo de si se trata de reglas de la lógica, máximas de la experiencia o principios de la ciencia. 
Es verosímil, aun con toda la dificultad que entraña este asunto, pensar en sentencias que se fundamenten en el desuso de las reglas de la lógica. De hecho, los principios formales del pensamiento correcto constituyen una exigencia que, de entrada, hay que tener en cuenta en la estructuración de cualquier demanda de casación con el fin de evitar el planteamiento de cargos que infrinjan el principio lógico de no contradicción ${ }^{57}$, infracción que se descarta en el caso de que los cargos se formulen en capítulos separados ${ }^{58}$. Pero lo que sí puede generar perplejidad es la invocación de un falso raciocinio motivado por máximas de la experiencia desconocidas por el sentenciador, cuando la jurisprudencia de la Corte establece el deber del casacionista de demostrar que la máxima de la experiencia que se invoca omitida en el fallo atacado, en efecto cumple con las condiciones para ser tal: es decir, que el argumento presentado a modo de "generalización empírica", es admitido como regla de la experiencia en el contexto y conglomerado social específicos ${ }^{59}$, con pretensiones de universalidad ${ }^{60}$. Puede afirmarse que en diferentes

57 En el libro IV de la Metafísica, Aristóteles establece que el principio más firme del pensamiento y sobre el cual es imposible equivocarse, es este: "es imposible que al mismo tiempo el mismo atributo pertenezca y no pertenezca al mismo sujeto en el mismo sentido", es decir, es imposible que la misma cosa sea y no sea al mismo tiempo. Aristóteles, Metafísica, Libro IV Capítulo III, 118 (Alianza Editorial, Madrid, 2011). Su enunciación lógica se puede leer como "no a la vez p y no p" ( $\neg(\mathrm{p} \bigotimes \neg \mathrm{p}))$. Según esta relación de oposición contradictoria, dos proposiciones manifiestamente contradictorias no pueden ser a la vez verdaderas ni pueden ser a la vez falsas, por lo que si A es verdadera, $\mathrm{O}$ es falsa y si A es falsa, $\mathrm{O}$ es verdadera. Las expresiones son mutuamente exclusivas, no pudiendo ser las dos verdaderas, e implicando la verdad de una la falsedad de la otra y viceversa. José Ferrater-Mora, Diccionario de filosofía, Tomo I, 638-685 (Editorial Ariel, Barcelona, 2002).

58 De hecho, las lecturas de este principio son varias. Para la jurisprudencia de la Sala Penal, en esencia, se quebranta este principio "cuando a través de varias causales de casación se hacen planteamientos inconciliables y excluyentes; cuando dentro de la misma causal v.gr. la primera, se aduce violación directa e indirecta de los mismos preceptos sustanciales, o se alega del mismo medio probatorio, error de hecho o de derecho por falsos juicios de existencia y de convicción, o cuando dentro del mismo cargo se presentan argumentaciones opuestas e irreconciliables". Corte Suprema de Justicia, Sala Penal, Proceso 4649, 13 de julio de 1990, magistrado ponente Jaime Giraldo-Ángel.

59 La jurisprudencia ha establecido que "quien invoque la vulneración de una regla de la experiencia, debe demostrar que el argumento presentado a modo de generalización empírica, es admitido como máxima de experiencia en el contexto y conglomerado social específicos, ocurrido lo cual debe confrontar las razones del tribunal respecto de la prueba que se dice valorada erradamente, con los parámetros que surgen de la máxima, y así verificar que la corporación desconoció los últimos". Corte Suprema de Justicia, Sala Penal, Proceso 16472, 21 de noviembre de 2002, magistrado ponente Jorge Aníbal Gómez-Gallego. Disponible en: http://190.24.134.97/WebRelatoria/csj/index.xhtml. Corte Suprema de Justicia, Sala Penal, Proceso 35621, auto de 2 de marzo de 2011, magistrado ponente Julio Enrique Socha-Salamanca. Disponible en: http://190.24.134.97/WebRelatoria/csj/index.xhtml

60 "Si lo que se plantea es la falta de consideración de una máxima de la experiencia aplicable 
conglomerados sociales pueden tener vigencia juicios que surgen de la observación y posterior generalización de casos concretos, y que indican que ciertos hechos se desarrollan siempre de una determinada manera. Empero, la referencia a construcciones teóricas relacionadas con las costumbres, cultura y cotidiano vivir de seres humanos en un contexto dado ${ }^{61}$, se contradice con la noción de universalidad que menciona la Corte, ya que la cultura o costumbre de un conglomerado social es algo particular sobre lo que no es posible asentar una máxima de la experiencia si se pretende atribuirle a esta el predicado de universalidad. Por esta razón, es necesario aclarar que si bien hay máximas de la experiencia que tienen esta última vocación, eso no significa que no pueda haber otras que denoten una normalidad o modo de ser habitual, obtenidas de la observación empírica y posterior generalización, no universales y propias de un grupo social determinado ${ }^{62}$.

El problema, se insiste, consiste en la manera de demostrar una regla de la experiencia, en el supuesto de que no se cuente dentro del expediente con una prueba pericial en la que se pueda sustentar su existencia, o cuando el juzgador desconoce una regla de tal naturaleza fácilmente deducible de la cotidianidad humana: en este orden de ideas, ¿sería necesario en la sustentación del cargo, citar alguna clase de estudio empírico, concepto o artículo de investigación, con el fin de demostrar que la proposición propuesta por el casacionista puede constituir una máxima de la experiencia? Es un

al caso, es deber del casacionista señalar la regla de experiencia que los juzgadores omitieron aplicar, acreditar que cumple los presupuestos para su formulación con pretensiones de universalidad, demostrar que de haber sido tenida en cuenta se habrían cambiado las conclusiones del razonamiento inferencial que se cuestiona, y demostrar que el yerro surtió efectos trascendentes en la decisión impugnada". Corte Suprema de Justicia, Sala Penal, Proceso 31522, auto de 18 de noviembre de 2009, magistrado ponente José Leonidas Bustos-Martínez. Disponible en: http://190.24.134.97/WebRelatoria/csj/index.xhtml

61 Corte Suprema de Justicia, Sala Penal, Proceso 36824, 12 de septiembre de 2012, magistrado ponente Julio Socha-Salamanca. Disponible en: http://190.24.134.101/corte/wp-content/ uploads/relatorias/pe/bloct2012/36824(12-09-12).doc

62 Con seguridad hay reglas de la experiencia desconocidas por los colombianos en otros países, en otras latitudes del planeta, o incluso en otras regiones de nuestro país, por lo que no parece correcto adjudicarle, como de su "esencia", el predicado de "universalidad" al concepto. Como sintetiza con acierto Álvaro Orlando Pérez-Pinzón, adentrándose en su verdadero alcance, la experiencia es el conocimiento que se obtiene de la práctica, de la observación, del diario discurrir, de las actuaciones normales de la vida de los seres humanos, y sus máximas se obtienen de la generalización de casos concretos, que permiten anticipar determinados sucesos. Álvaro Orlando Pérez-Pinzón, Introducción al estudio de la casación penal, 192-193 (Temis, Bogotá, 2014). 
interrogante interesante, porque la jurisprudencia le ha trasladado al casacionista la carga de tal demostración, de manera genérica y sin indicar un método. Esta alternativa, en principio y salvo mejor indicación metodológica por parte de la jurisprudencia, parece razonable para demostrarle a la Corte que la valoración y la motivación del acervo probatorio no fueron racionales.

Ciertamente, la identificación de máximas de la experiencia de vigencia social indiscutible constituye el primer paso para la prueba del dolo, muy probablemente la cuestión más difícil de acreditar en el proceso pena $1^{63}$. Es loable el intento de la jurisprudencia penal de antaño de mencionar indicios que racionalmente pueden conducir a la inferencia del dolo en determinados delitos ${ }^{64}$, pero si se quiere avanzar en una metodología adecuada para la proposición del falso raciocinio, debería hacerse a título enunciativo una sistematización de los indicios y las máximas de la experiencia más frecuentes, según los casos, los delitos y el contexto social en el que se desarrollan ${ }^{65}$, todo con el fin de afianzar más certidumbre en este aspecto de la violación indirecta por falso raciocinio.

A pesar de la consagración jurisprudencial de la causal, realmente es necesario preguntarse si por lo menos en el sistema procesal penal implementado con la Ley 906 de 2004 puede hablarse de un método de valoración de la prueba de conformidad con la sana crítica. Y el problema no es baladí, porque no son descartables las críticas que se le han planteado, tales como: a) la pretensión

63 De esta manera, solo cuando el juez encuentre en la interacción social "una regla de experiencia de vigencia indiscutible según la cual, presupuestos ciertos datos objetivos, una persona por fuerza ha sido conocedora de determinados hechos, podrá atribuir correctamente dichos conocimientos al concreto acusado". RAMÓn RAGUÉS I VALLÈs, Consideraciones sobre la prueba del dolo, 4 Revista de Estudios de la Justicia, REJ, 13-26, 20 (2004). Disponible en: http://web. derecho.uchile.cl/cej/recej/recej4/archivos/PRUEBA\%20DEL\%20DOLO\%20RAGUES\%20 _8_.pdf. Desarrolla el planteamiento con profundidad en RAMÓN RAGUÉS I VALLÈs, El dolo y su prueba en el proceso penal, 323-353 (José María Bosch Editor, Barcelona, 1999).

64 Por ejemplo, la enunciación de hechos que permiten inferir el dolo de matar, como el medio de agresión empleado, la distancia, la dirección y el número de golpes inferidos, la calidad del arma, las condiciones de modo, tiempo y lugar en las que se efectuó el ataque y la región anatómica comprometida. Al respecto, Corte Suprema de Justicia, Sala Penal Proceso 278, 27 de octubre de 1986, magistrado ponente Lisandro Martínez-Zúñiga. Corte Suprema de Justicia, Sala Penal, Proceso 19646, 20 de octubre de 2005, magistrado ponente Yesid Ramírez. Disponible en: http://190.24.134.97/WebRelatoria/csj/index.xhtml

65 Ante la prueba de los hechos psíquicos, se refiere Michele TARUfFo a la tendencia jurisprudencial de tipificar "esquemas" de indicios para supuestos de hecho particulares, y cuya presencia normalmente implica la existencia de tales hechos. Michele TARUffo, La prueba de los hechos, 164-165 (Trotta, Madrid, 2005). 
de aplicabilidad "universal" del método para todos los medios de prueba, cuando inicialmente solo fue prescrito para la apreciación del testimonio ${ }^{66}$; b) la fundamentación de sus reglas, parecidas más a suposiciones o conjeturas, en principios no demostrados y casi siempre indemostrables; c)la sana crítica es ineficaz para apreciar la prueba documental, la prueba pericial, la inspección o cualquier otro medio válido para demostrar, porque carece de una metodología de carácter científico que permita penetrar en el conocimiento de los elementos estructurales de cada uno de los medios de prueba y de las conexiones sistemáticas que le otorgan unidad y coherencia, con lo cual se desentraña el mensaje probatorio; d) el artículo 380 de la Ley 906 de 2004 no menciona la sana crítica de forma directa, e indica en su segundo inciso que los criterios para apreciar cada uno de los medios de prueba serán señalados en el respectivo capítulo, por lo que en cada uno de los capítulos respectivos se enuncian claramente los criterios técnico-científicos para apreciar cada medio de prueba; en este orden de ideas, se tiene que para un sector de la doctrina el sistema técnico-científico de valoración probatoria es el que rige en el estatuto procesal penal de $2004^{67}$. Estas observaciones no son desdeñables y atraen un estudio más amplio de la cuestión; sin embargo, de las críticas no se deduce a priori la inutilidad de la causal por falso raciocinio, dado que eventualmente pueden presentarse sentencias con protuberantes fallos en sede de la lógica, o en relación con principios científicos indubitables o máximas de la experiencia, todos ellos constatables y con fundamento en las normas que establecen en la Ley 906 de

66 En nuestro medio, el autor Gustavo Morales-Marín enfatiza esta tesis: "Generalmente, en la doctrina universal, las reglas de la sana crítica se han constituido en método para la apreciación del testimonio. EdUARdo J. Couture, en su obra 'Las reglas de la sana crítica', afirma que estas están dirigidas 'al modo de apreciación de la prueba de testigos'. De manera análoga fue reconocido, en nuestro medio, por el tratadista ANTONIO RoCHA-ALVIRA. En rigor científico, no es posible extender el método de la sana crítica a la valoración de los demás medios probatorios. La sana crítica carece de recursos teóricos y de metodología propia, específica, como para apreciar medios probatorios distintos del testimonio. Los demás medios de prueba tienen muy diversa estructura, muy diversos elementos integradores, lo cual exige una especial metodología para que se aprecie, con eficacia, esos elementos que los constituyen y particulariza". Gustavo Morales-Marín, Ciencia de las pruebas penales. Sistema acusatorio, 132 (Grupo Editorial Ibáñez, Bogotá, 2014).

67 Gustavo Morales-Marín, Ciencia de las pruebas penales. Sistema acusatorio, 142-145 (Grupo Editorial Ibáñez, Bogotá, 2014). 
2004 criterios de apreciación de los medios de prueba, y que plasman verdaderos ejercicios de sana crítica ${ }^{68}$.

Una vez revisadas las exposiciones jurisprudenciales sobre la técnica de las causales, es indudable que la Sala de Casación Penal debe convertirse en un órgano vigilante de la correcta aplicación de la norma jurídico-penal, para verificar los yerros invocados mediante la revisión puntual de la motivación de la valoración probatoria $^{69}$. Creemos claramente que una motivación racional de la decisión judicial sería difícilmente cuestionable por medio del recurso extraordinario, ya que la sentencia contendría un análisis sin distorsión alguna de las pruebas de cargo y de descargo ${ }^{70}$, para señalar su mérito persuasivo de conformidad con las reglas de la sana crítica y "en conjunto". Ahora, al tratarse de la convicción judicial de culpabilidad penal desde esta perspectiva de valoración racional $^{71}$, aquella debe considerarse comprobada si la hipótesis

68 Es decir, incluso las normas de la Ley 906 de 2004 sobre apreciación de los medios de prueba incorporan ejercicios de sana crítica, por lo que este concepto encontraría una mejor concreción: "En efecto, el mandato genérico del artículo 380 es el de apreciación de las pruebas en conjunto de acuerdo con las reglas de la sana crítica, generalidad que, a su vez, se singulariza en los artículos 404, 420 y 432 ejusdem en las [sic] que se establecen criterios de apreciación, y sin excepción apuntan a ejercicios de sana crítica en punto de la idoneidad de los órganos de prueba, precisión, claridad, verosimilitud, pertinencia, convergencias y no contradicción". Corte Suprema de Justicia, Sala Penal, Proceso 32270, 29 de septiembre de 2010, magistrado ponente Yesid Ramírez-Bastidas. Disponible en: http:/190.24.134.97/WebRelatoria/csj/index. xhtml

69 Un deber fundamental de la Corte de Casación, indica EnRique BaCigalupo-Zapater, es velar por la calidad de la motivación de las decisiones judiciales, al controlar los motivos de hecho, ya que una incorrecta determinación del hecho repercute en una incorrecta aplicación del derecho, poniéndose en funcionamiento la norma jurídica sobre supuestos fácticos errados. Así, concluye que "en la práctica la exigencia de motivación se refiere a la obligación de los tribunales de dar respuesta fundada a toda enunciación de hechos realizada por las partes, cuando, de ser estos establecidos, serían susceptibles de influir sobre la responsabilidad penal del procesado". Enrique Bacigalupo-Zapater, Presunción de inocencia, "in dubio pro reo" y recurso de casación, Tomo 41 Anuario de Derecho Penal y Ciencias Penales, 2, 365-386, 375 (1988). Disponible en: https://dialnet.unirioja.es/descarga/articulo/46325.pdf

70 Una valoración racional reclama la ponderación de todos y cada uno de los elementos probatorios actuados en el proceso, por lo que se opone al invento de hechos y pruebas, o al acto de ignorar pruebas practicadas. Para Michele TARuffo, es un principio de "orden racional" el que exige que la comprobación del hecho en juicio ocurra sobre la base de todas las pruebas que han sido adquiridas en el proceso, y que se han revelado relevantes y útiles para establecer los hechos de la causa. Eso significa que todas las pruebas adquiridas sean tomadas en consideración por el juez, y que si ciertas pruebas vienen a considerarse no creíbles o sin eficacia probatoria, el juez dé cuenta de esta situación en la motivación de la sentencia. Michele Taruffo, La valutazione della prova. Prova libera e prova legale. Prove e argomenti di prova, 108 Quaderni del Consiglio Superiore della Magistratura, La prova nel Processo Civile, Volume Secondo, 423-446, 444 (1999). Disponible en: http://www.csm.it/quaderni/quad_108/ quad_108_25.pdf

71 Como la que plantea con acierto JoRdi FerRER-BELTRÁn al aplicar el método de la probabilidad 
acusatoria explica los hechos coherentemente y refuta las hipótesis plausibles en el proceso compatibles con la inocencia del acusado, por lo que se entiende en este caso desvirtuada la presunción de inocencia ${ }^{72}$, condiciones que fallarían y que serían recurribles en casación (por lo que deben ser estudiadas por la Corte) en la medida en que el juzgador omita la prueba de un hecho que pueda variar la sentencia condenatoria ante su trascendencia para la inocencia, distorsione el contenido material de una prueba - generando la variación de la esencia de un hecho relevante para la hipótesis de inocencia-, o razone de forma incorrecta desconociendo las reglas de la lógica, las máximas de la experiencia y los conocimientos científicos $^{73}$.

\section{EL ROL DE LA VERDAD EN LA CASACIÓN PENAL POR VÍA INDIRECTA}

\section{La casación penal debería convertirse, en relación con las causales que desarrollan los errores de hecho en la apreciación de las prue- bas, en el extremo mecanismo de control legal por antonomasia para corregir los falsos raciocinios de los jueces o sus inadecuados ejercicios interpretativos de la prueba, e incluso para poner coto}

inductiva. Según su planteamiento, el juez o tribunal actúan análogamente a como lo hace la comunidad científica, al evaluar el grado de corroboración de una hipótesis a la luz de las demás hipótesis rivales tomadas en consideración, los datos disponibles, los experimentos (o sea, las pruebas) y las inferencias realizadas a partir de ellos, valorando el apoyo que los elementos de juicio aportan a las hipótesis fácticas sobre lo ocurrido. Por lo tanto, considera que la hipótesis de culpabilidad quedaría probada, si concurren dos condiciones: "1) la hipótesis debe explicar los datos disponibles, integrándolos de forma coherente, y las predicciones (de nuevos datos) que la hipótesis permita formular deben haber sido confirmadas. 2) Deben haberse refutado todas las demás hipótesis plausibles explicativas de los mismos datos que sean compatibles con la inocencia del acusado, excluidas las meras hipótesis ad hoc". JORDI Ferrer-Beltrán, La valoración racional de la prueba, 147 (Marcial Pons, Madrid, 2007).

72 Desde luego, habría que aplicar el in dubio pro reo que impediría una condena, si junto a la hipótesis acusatoria permanecen otras hipótesis no desmentidas en competencia con ella. Luigi Ferrajoli, Derecho y razón. Teoría del garantismo penal, 152 (Trotta, Barcelona, 1997).

73 "Cuando la valoración de la prueba fundamenta la certeza respecto de los hechos mediante un razonamiento lógicamente incorrecto (por ejemplo, deduce la autoría del procesado de las declaraciones de los testigos que dicen que este no ha sido el autor), o extrayendo conclusiones contrarias a los principios de la experiencia (por ejemplo, incompatibles con la ley de la gravedad) o contrarias a conocimientos científicos (por ejemplo, las mediciones de la impregnación del alcohol en la sangre), el tribunal de casación podrá, en consecuencia, apreciar infracción de ley por violación de una norma de carácter sustancial (in dubio pro reo)". ENRIQUE Bacigalupo-Zapater, Presunción de inocencia, "in dubio pro reo" y recurso de casación, Tomo 41 Anuario de Derecho Penal y Ciencias Penales, 2, 365-386, 382 (1988). Disponible en: https:// dialnet.unirioja.es/descarga/articulo/46325.pdf 
al decisionismo procesal ${ }^{74}$, que deviene en sentencias de cuño subjetivista irracionales e injustas, que no se atienen a la verdad en el proceso al apartarse de la obligada valoración justificada, completa y racional de la prueba con fundamento en referentes empíricos concretos, al venir determinadas por consideraciones extrajurídicas (concepciones morales o políticas, prejuicios, "intuiciones", inclinaciones de ánimo arbitrarias, subjetividades ${ }^{75}$, etc.) o simplemente, por razonamientos erróneos. No puede haber sentencia justa que se erija sobre una fijación falsa de los hechos, por lo que la búsqueda de la verdad constituye el fundamento jurídico-político de toda sentencia penal, que sin lugar a duda permite orientar la conducta de los ciudadanos en el sentido crucial del respeto por las normas jurídicas ${ }^{76}$.

La verdad ha sido objeto de elocuentes debates en distintas disciplinas del saber y es un tema predilecto en el campo filosófico ${ }^{77}$.

74 El decisionismo procesal, como elemento de la epistemología antigarantista, según LuIGI FERRAJOLI, es "el efecto de la falta de anclajes empíricos precisos y de la consiguiente subjetividad de los presupuestos de la sanción en las aproximaciones sustancialistas y en las técnicas de prevención y defensa social. Esta subjetividad se manifiesta en dos direcciones: por un lado, en el carácter subjetivo del tema procesal, consistente más que en hechos determinados en condiciones o cualidades personales, como la pertenencia del reo a 'tipos normativos de autor' o su congénita naturaleza criminal o peligrosidad social; pero, por otro lado, se manifiesta también en el carácter subjetivo del juicio, que, en ausencia de referencias fácticas exactamente determinadas, resulta basado en valoraciones, diagnósticos o sospechas subjetivas antes que en pruebas de hecho. El primer factor de subjetivación genera una perversión inquisitiva del proceso, dirigiéndolo, antes que hacia la comprobación de hechos objetivos (o más allá de ella), hacia el análisis de la interioridad de la persona juzgada. El segundo degrada la verdad procesal de verdad empírica, pública e intersubjetivamente controlable, al convencimiento íntimamente subjetivo y, por tanto, irrefutable del juzgador". Luigi Ferrajoli, Derecho y razón. Teoría del garantismo penal, 43 (Trotta, Barcelona, 1997).

75 E incluso, por la imaginación. Para Michel de Montaigne, "fortis imaginatio generat casum" (una fuerte imaginación genera el hecho). Michel de Montaigne, Los ensayos (según la edición de 1595 de Marie de Gournay), 106 (Acantilado, Barcelona, 2007).

76 "Solo si el proceso judicial cumple la función de determinar la verdad de las proposiciones referidas a los hechos probados podrá el derecho tener éxito como mecanismo pensado para dirigir la conducta de sus destinatarios. Solo podrá influirse en la conducta de los hombres y mujeres para que no maten si, efectivamente, el proceso cumple la función de averiguar quién mató y le impone la sanción prevista por el derecho". JoRd FerRer-BELtrán, La valoración racional de la prueba, 30 (Marcial Pons, Madrid, 2007).

77 En su libro Adiós a la verdad (2008), Gianni Vattimo critica la teoría de la verdad como correspondencia, resumida en la formulación clásica medieval veritas est adaequatio rei et intellectus (la verdad es la concordancia entre ser y entendimiento). Para el filósofo italiano, esta es una tesis peligrosa en política: "Puesto que la verdad es siempre un hecho interpretativo, el criterio supremo en el cual es posible inspirarse no es la correspondencia puntual del enunciado respecto de las 'cosas', sino el consenso sobre los presupuestos de los que se parte para valorar dicha correspondencia". En otro lugar concluye que "la verdad como absoluta correspondencia objetiva, entendida como última instancia y valor de base, conduce a la república de los filósofos, los expertos y los técnicos, y, al límite, al Estado ético, que pretende poder decidir 
Sin entrar de lleno en los ricos contenidos de estas densas discusiones, al menos como punto de partida para examinar el tema de la verdad en el proceso judicial lo cierto es que algunos autores han fijado particularmente su atención en el clásico criterio propuesto por Alfred TARSKi, según el cual el enunciado "la nieve es blanca" es verdadero si y solo si, la nieve es blanca ${ }^{78}$. En el contexto del proceso judicial, la verdad de la determinación de los hechos se funda exclusivamente en las pruebas que justifican la decisión del juzgador, y que constituyen en esencia la base cognoscitiva en la que encuentra plena justificación el convencimiento de que un enunciado corresponde a la realidad de los hechos del caso $^{79}$ : con esto se concluye que la "verdad" de los enunciados sobre los hechos relevantes del proceso, depende de la "realidad" de estos últimos, premisa principal del modelo epistemológico cognoscitivista, según el cual los procedimientos de fijación de los hechos se dirigen

cuál es el verdadero bien de los ciudadanos, incluso contra su opinión y preferencias. Allí donde la política busca la verdad no puede haber democracia”. Gianni Vattimo, Adiós a la verdad, 28-29 (Gedisa, Barcelona, 2010).

78 Michele Taruffo, Simplemente la verdad. El juez y la construcción de los hechos, 98 (Daniela Accatino-Scagliotti, trad., Marcial Pons, Madrid, 2010). Esta es la famosa concepción semántica de la verdad. LuIGI FerRajoli sigue el mismo criterio y lo asume como principio del modelo cognoscitivista de jurisdicción penal que plantea en el capítulo primero de su monumental obra Derecho y razón: "Según la definición de Alfred Tarski, una proposición 'P' es verdadera si y solo si, 'p', donde 'P' está por el nombre metalingüístico de la proposición y 'p' por la proposición misma: por ejemplo, la oración la nieve es blanca es verdadera si, y solo si, la nieve es blanca. Si aplicamos esta equivalencia al término 'verdadero' tal y como es predicable de la proposición fáctica y de la jurídica en las que se puede descomponer la proposición jurisdiccional 'Ticio ha cometido culpablemente tal hecho denotado por la ley como delito', obtenemos por sustitución las dos siguientes equivalencias: a) la proposición 'Ticio' ha cometido culpablemente tal hecho es verdadera si y solo si, Ticio ha cometido culpablemente tal hecho, y b) la proposición 'tal hecho está denotado por la ley como delito' es verdadera si, y solo si, tal hecho está denotado por la ley como delito. Estas dos equivalencias definen, respectivamente, la verdad fáctica y la verdad jurídica, respecto de las que sirven para aclarar las distintas referencias semánticas, que en el primer caso son los hechos ocurridos en la realidad y en el segundo las normas que hablan de ellos. Y definen, conjuntamente, la verdad procesal (o formal)". Luigi Ferrajoli, Derecho y razón. Teoría del garantismo penal, 48 (Trotta, Barcelona, 1997). Este modelo cognoscitivista defendido para la jurisdicción, "postula un realismo mínimo, y por tanto concibe el conocimiento de hechos como la relación entre sujeto cognoscente y mundo real que permite calificar los resultados del conocimiento como verdaderos o falsos, dependiendo de que los acontecimientos que describen hayan sucedido o no". MARINA GASCÓN-ABELLÁn, Los hechos en el derecho, bases argumentales de la prueba, 54 (Marcial Pons, Madrid, 2010). En la doctrina colombiana sigue de cerca estos planteamientos para coadyuvar la teoría de la verdad como correspondencia, y aplicarla a las nociones de adecuación típica (integrada por el tipo penal y la conducta humana), adecuación antijurídica y adecuación culpable. Germán PABón-Gómez, De la casación en el sistema acusatorio, 209, 211 (Grupo Editorial Ibáñez, Universidad de los Andes, Bogotá, 2011).

79 Michele Taruffo, Simplemente la verdad. El juez y la construcción de los hechos, 100 (Daniela Accatino-Scagliotti, trad., Marcial Pons, Madrid, 2010). 
a la formulación de enunciados fácticos que, en definitiva, serán verdaderos si los hechos que describen han sucedido y falsos, en caso contrario ${ }^{80}$.

MARINA GASCÓN-ABELLÁN reconoce que esta concepción semántica de la verdad de Tarski es una rehabilitación de la teoría de la correspondencia ${ }^{81}$, ya que ofrece una definición de la verdad (de las oraciones) en términos de "satisfacción", entendida esta como una relación entre oraciones abiertas y secuencias de objetos (del mundo real); ahora, esta concepción es coherente con el modelo epistemológico cognoscitivista, mínimamente realista, en el cual los enunciados fácticos se entienden como meras descripciones de hechos que tienen una existencia independiente de esos enunciados; la pretensión de quien los formula es referirse a una realidad externa ${ }^{82}$.

En el plano de la fijación judicial de los hechos, el cognoscitivismo es adecuado desde el punto de vista conceptual, práctico y valorativo. Resulta conceptualmente adecuado, porque es el que más se adecúa a las intuiciones de los hablantes y a las de quienes participan en el procedimiento judicial, ya que cuando se le pide al testigo que diga la verdad, se le pide que describa los hechos tal como sucedieron en el mundo real; es prácticamente adecuado, porque en el procedimiento judicial de fijación de los hechos lo que más interesa de los enunciados fácticos es la información empírica que proporcionan, es decir, cuáles son los hechos que han tenido lugar; y es valorativamente adecuado, si se tiene en cuenta que las teorías de la coherencia ${ }^{83}$ y de la aceptabilidad justificada ${ }^{84}$

80 "En otras palabras, la fijación judicial de los hechos no puede ser, por ejemplo, consecuencia del puro decisionismo o constructivismo sino el resultado de un juicio descriptivo de hechos a los que se atribuye 'existencia independiente'. Por ello, el concepto de verdad requerido por el modelo es el semántico de la correspondencia y el principal criterio de verdad es de la contrastación empírica". MARINA GASCÓN-ABELLÁN, Los hechos en el derecho, bases argumentales de la prueba, 49 (Marcial Pons, Madrid, 2010).

81 Marina Gascón-Abellán, Los hechos en el derecho, bases argumentales de la prueba, 64 (Marcial Pons, Madrid, 2010).

82 Marina Gascón-Abellán, Los hechos en el derecho, bases argumentales de la prueba, 60 (Marcial Pons, Madrid, 2010).

83 Para esta teoría, un enunciado es verdadero si pertenece a un sistema coherente de enunciados. La verdad consiste en la concordancia de los enunciados entre sí. MARINA GASCón-Abellán, Los hechos en el derecho, bases argumentales de la prueba, 52 (Marcial Pons, Madrid, 2010).

84 Según esta teoría, la verdad de un enunciado se concibe en términos de "aceptabilidad justificada". Un enunciado es verdadero si está justificado creer que es verdadero porque sirve a algún fin (versión "instrumentalista") o porque es aceptado (versión "consensualista"). MARINA GASCÓN-ABELLÁn, Los hechos en el derecho, bases argumentales de la prueba, 51 (Marcial Pons, Madrid, 2010). 
son radicalmente inaceptables en la jurisdicción, en cuanto para justificar las decisiones judiciales no es suficiente que "satisfagan" o "tengan éxito" o que sean "aceptadas", sino que basta y es necesario que sus presupuestos fácticos sean verdaderos en el sentido de la correspondencia con los hechos ${ }^{85}$.

Además, el modelo comentado se acomoda a una actitud epistemológica no dogmática, que contempla la posibilidad de pensar en la falsedad de las hipótesis; al decir de Luigi Ferrajoli, "permite sostener la hipótesis de que un imputado podría ser inocente (o culpable) aunque tal hipótesis haya sido rechazada en todas las instancias de un proceso, y esté en contraste con todas las pruebas disponibles" $" 86$. Esto significa que la sentencia puede ser cuestionada como errónea, por ejemplo cuando se interpone y sustenta la demanda de casación por errores en la apreciación probatoria por falsos juicios de existencia o falsos juicios de identidad: en ambos casos, los enunciados fácticos de la sentencia no corresponden a la realidad que se infiere de las pruebas del proceso.

Una justicia penal sin verdad equivale a un sistema de arbitrariedad. La función judicial es eminentemente una actividad cognoscitiva, en la cual las decisiones deben fundamentarse en juicios de hecho verificables conforme a las investigaciones empíricas tendientes a la prueba de tales juicios, y que generan la aplicación de una consecuencia jurídica conforme a la interpretación de las normas que califican el supuesto de hecho como delito. Michele TARuffo ha sido insistente en la necesidad de tener en cuenta en el proceso la calidad de la decisión judicial y, por lo tanto, la determinación de la verdad bajo el supuesto de que en vigencia del principio de legalidad la jurisdicción tiene como fin la determinación y la actuación del derecho, lo cual implica que la decisión debe fundarse en la correcta aplicación de la ley a las circunstancias del caso concreto ${ }^{87}$. De esta idea se infiere que la corrección jurídica de la sentencia debe fundarse en una determinación verdadera de los hechos del caso ${ }^{88}$.

85 Marina Gascón-Abellán, Los hechos en el derecho, bases argumentales de la prueba, 62 (Marcial Pons, Madrid, 2010).

86 Luigi Ferrajoli, Derecho y razón. Teoría del garantismo penal, 67 (Trotta, Barcelona, 1997).

87 Michele Taruffo, Simplemente la verdad. El juez y la construcción de los hechos, 133 (Daniela Accatino-Scagliotti, trad., Marcial Pons, Madrid, 2010).

88 Para los procesos que reconocen derechos, para Taruffo es claro que este principio se concreta en el sentido de que "un sujeto es efectivamente titular de un derecho solo si son verdaderos los hechos de los que depende en concreto la existencia de ese derecho. Por tanto, una sentencia 
Así las cosas, si no ha tenido ocurrencia el supuesto de hecho del que depende la aplicación de la norma jurídica, esta no puede ser aplicada al caso, por lo que la decisión será defectuosa y jurídicamente errónea si la norma es aplicada faltando aquel presupuesto ${ }^{89}$.

Una vez sentadas las bases metodológicas en las que la jurisprudencia de la Corte se ha fundado para considerar correctamente planteadas en sede de casación las causales que se agrupan dentro de la violación indirecta, es necesario elaborar un juicio crítico definitivo respecto a si tales bases son funcionales de cara al desarrollo del modelo epistemológico cognoscitivista de jurisdicción penal, en el cual la verdad de las afirmaciones sobre los hechos cobra un papel fundamental. Sin lugar a dudas, algunos reparos muy puntuales ya formulados en este artículo, como la pretensión indebida de confundir la evaluación integral de la prueba con su enunciación genérica, la deseada invocación de un análisis de la prueba que genere un convencimiento natural y social, la pedagogía clara de las causales propias de la violación indirecta para facilitar el acceso a la administración de justicia, la revisión de la teoría del delito aplicable al caso, el análisis de la hipótesis acusatoria según los hechos probados en el juicio considerando su coherencia y capacidad de refutación de otras hipótesis plausibles compatibles con la inocencia y la acreditación de máximas de la experiencia por medio de una metodología clara, que surja de un deseable esfuerzo de sistematización por parte de la Corte y que no haga exclusivo hincapié en la noción de universalidad, procuran coadyuvar al objetivo del citado modelo epistemológico, esto es, afirmar la correcta aplicación de la norma jurídica mediante la fijación verdadera de los supuestos de hecho.

Sin embargo, un problema conspira en contra de este ideal, que hace parte del modo en que, en ciertas ocasiones, los sustanciadores

que afirma, respecto de un sujeto, la existencia de un derecho, debe haber determinado de forma verídica la realización de todas las condiciones de hecho — además de las del derechonecesarias para que se pueda sostener que ese sujeto es realmente titular de ese derecho". Michele TARuffo, Simplemente la verdad. El juez y la construcción de los hechos, 133 (DaniEla Accatino-Scagliotti, trad., Marcial Pons, Madrid, 2010). En el proceso penal, puede decirse, de forma análoga, que una sentencia que afirma — respecto de un sujeto — la responsabilidad penal, debe determinar de forma verídica las condiciones de hecho y de derecho necesarias para sostener que ese sujeto es responsable por la realización de una conducta punible.

89 Michele TARuffo, Simplemente la verdad. El juez y la construcción de los hechos, 134 (Daniela Accatino-Scagliotti, trad., Marcial Pons, Madrid, 2010). 
del recurso extraordinario analizan y proyectan las demandas. Una lectura errada del expediente, sin cotejar los fundamentos de la demanda con las pruebas consignadas en el plenario, puede llevar a graves errores en la proyección de las decisiones de la Sala Penal, en las cuales no se identifiquen los falsos juicios de existencia o de identidad invocados por el demandante, o los patentes yerros en la aplicación de las reglas de la sana crítica. La razón: una lectura descuidada del expediente, generado las más de las veces por el afán de defender, a toda costa y bajo supuestos de hecho equivocados (derivados de la mala lectura), los argumentos que tuvo en cuenta el tribunal para confirmar la sentencia apelada, ignorando la existencia de pruebas enervantes de las conclusiones del fallo $\mathrm{o}^{90}, \mathrm{o}$ la aparición ostensible de inferencias contrarias a la sana crítica ${ }^{91} \mathrm{o}$ de burdas tergiversaciones en el contenido material de las pruebas. Precisamente, ese afán de defensa se advierte en la postulación, por

90 Algunos fallos son muestra elocuente de ello. En la sentencia de 9 de marzo de 2016 (Proceso 46483), la Sala Penal decidió no casar la condena a un funcionario de la Caja Agraria (autor) $\mathrm{y}$ a un constructor (determinador) por el delito de peculado por apropiación, ante la no terminación de una obra de interés social por la supuesta pérdida de los desembolsos del dinero prestado por la entidad financiera. Aquí, la sentencia menciona el certificado de Fiduagraria, en la que se certificó que los dineros entregados por la Caja Agraria fueron invertidos en la obra de urbanización, sin que esta construcción se hubiera podido terminar por una situación de fuerza mayor derivada de la liquidación de la entidad financiera mencionada. A pesar de que estas circunstancias fueron suficientes para que el procurador delegado para la casación penal en ese proceso emitiera dos conceptos favorables a la casación del fallo, en los fundamentos de la decisión, la Corte desconoció la prosperidad del falso juicio de existencia por omisión y reiteró los argumentos del tribunal, sin declarar, de manera ilógica, la atipicidad por el delito de peculado por apropiación con base en la prueba del certificado, determinante de tal conclusión. Corte Suprema de Justicia, Sala Penal, Proceso 46483, 9 de marzo de 2016, magistrado ponente Luis Guillermo Salazar-Otero. Disponible en: http://190.24.134.97/Web Relatoria/csj/index.xhtml

91 En la sentencia de 25 de agosto de 2010 (Proceso 32964), en un caso de homicidio en el que el procesado estaba embriagado y causó la muerte de dos personas al cruzar con su vehículo un semáforo en rojo, la Corte no casó el fallo condenatorio a título de dolo eventual. A pesar de que se invocaron en la demanda falsos raciocinios encaminados a demostrar que en los eventos debidamente probados no podía inferirse la afirmación de que el procesado se representó como probable el resultado y dejó su producción librada al azar (ya que se pasó el semáforo en rojo, estaba embriagado e iba a velocidad excesiva) con base en la infracción de reglas de la experiencia fundamentales para inferir razonablemente que en tales circunstancias era imposible predicar el injusto típico en la modalidad de dolo eventual, la Sala Penal de la Corte defendió constantemente la decisión del tribunal concluyendo, de forma cuestionable, que no se trataba de un supuesto de culpa, y que el procesado en esas condiciones se pasó un semáforo en rojo creando un peligro concreto de producción del resultado, del que era consciente y tuvo la oportunidad de evitarlo. Corte Suprema de Justicia, Sala Penal, Proceso 32964, 25 de agosto de 2010, magistrado ponente José Leonidas Bustos-Martínez. Disponible en: http://190.24.134.97/WebRelatoria/csj/index.xhtml 
parte de la Corte, de meros alegatos defensivos de las decisiones de los inferiores ${ }^{92}$.

Otra práctica cuestionable, ya advertida y reprochada por la Corte Constitucional en la sentencia SU635-15 ${ }^{93}$, es que la Sala Penal de la Corte Suprema inadmita las demandas de casación por razones de fondo, con la eventual manía (no planteada en esta sentencia) de resolver directamente los cargos sin hacer una lectura sopesada del expediente, citando amplios apartes de la sentencia del tribunal que conoció la apelación para defender su postura y sin proponer razonamientos propios. El debido proceso indica que la demanda de casación solamente puede ser inadmitida por incumplimiento de los requisitos formales para su presentación: de cumplirlos, debe procederse a su admisión y adelantar las etapas subsiguientes $^{94}$, sin que sea viable resolver de fondo y al mismo tiempo inadmitir la demanda, ya que se afectaría la motivación de la decisión al incurrir en incongruencia entre la parte motiva y la parte resolutiva de la providencia.

Una condición indiscutible para propender por una aplicación correcta del derecho es la adecuada fijación de los hechos del caso concreto, ideal que con estos inconvenientes se vería frustrado, en perjuicio de la vigencia de un orden justo. Por consiguiente, es evidente que los equivocados fallos de la Sala Penal de la Corte deberán ser discutidos en sede de tutela contra providencia judicial, al invocar el accionante la configuración del defecto fáctico como causal especial de procedibilidad de la acción constitucional, en

92 Coincide con esta crítica el tratadista Fernando Velásquez-Velásquez, quien hace el comentario a propósito de la manera en que la Sala Penal en la sentencia de 25 de agosto de 2010 respondió a la demanda de casación formulada. Fernando Velásquez-Velásquez \& Christian WOLFFHÜGEL-GUTIÉRREZ, La diferencia entre el dolo eventual y la culpa consciente en la reciente jurisprudencia, 6 Cuadernos de Derecho Penal, 99-181, 165 (2011). Disponible en: http://revistas. usergioarboleda.edu.co/index.php/cuadernos_de_derecho_penal/article/viewFile/395/342

93 Corte Constitucional de Colombia, Sentencia SU635-15, 7 de octubre de 2015, magistrado ponente Jorge Ignacio Pretelt-Chaljub. Disponible en: http://www.corteconstitucional.gov. co/relatoria/2015/su635-15.htm

94 Por eso, "se ha indicado que el proceso de casación está compuesto por diversas etapas las cuales se agotan de manera progresiva, constituyéndose cada una en condición de la siguiente y en un impedimento para retroceder a las fases ya superadas. De este modo, existen tres etapas dentro del trámite de casación, el primero consistente en la interposición y concesión de este recurso; el segundo se refiere a la admisión del mismo por parte de la Corte Suprema de Justicia; y, finalmente, es en la última etapa en donde se toman las decisiones sobre la estimación del asunto puesto en conocimiento del Alto Tribunal". Corte Constitucional de Colombia, Sentencia SU635-15, 7 de octubre de 2015, magistrado ponente Jorge Ignacio Pretelt-Chaljub. Disponible en: http://www.corteconstitucional.gov.co/relatoria/2015/su635-15.htm 
cualquiera de sus modalidades ${ }^{95}$ (por ejemplo, por omisión de valoración, valoración caprichosa e irracional, etc.) según sea el caso.

$95 \mathrm{Al}$ respecto, Corte Constitucional, Sentencia T-1100-08, 6 de noviembre de 2008, magistrado ponente Humberto Antonio Sierra-Porto. Disponible en: http://www.corteconstitucional.gov. co/relatoria/2008/t-1100-08.htm 


\section{CONCLUSIONES}

En materia de violación indirecta de la ley sustancial por errores de hecho en la apreciación de la prueba, debe concluirse que las causales de falso juicio de existencia y de falso juicio de identidad pretenden precisamente la corrección o enmienda de estos errores in iudicando, que al final producen una falsa fijación de los supuestos de hecho que conduce, por lo tanto, a una errónea aplicación de la ley. En definitiva, si no ha tenido ocurrencia el supuesto de hecho que condiciona la aplicación de la norma jurídico-penal y el juzgador — no obstante esta situación — la aplica, bien sea por un falso juicio de existencia, al imaginarse la prueba de un hecho inexistente u omitir el hecho que desvirtúa el supuesto fáctico del tipo penal, o por incurrir en un falso juicio de identidad al tener como verdadero un juicio sobre un hecho distinto al que en realidad puede inferirse de la prueba, por adición, tergiversación o cercenamiento de la misma, la Sala Penal de la Corte Suprema de Justicia debe proceder a la corrección de estos errores casando la sentencia de segunda instancia, y dictando el fallo sustitutivo o de reemplazo que sea del caso, siempre y cuando la demanda de casación haya sido debidamente sustentada. En este orden de ideas, estas causales encuentran sustento en el modelo epistemológico cognoscitivista propio de la jurisdicción penal, en el que se aspira a alcanzar, en la mayor medida posible, una verdad entendida como correspondencia, así sea aproximada (en cuanto es imposible una verdad absoluta que refleje con exactitud la historicidad), pero jamás arbitraria, entre los enunciados fácticos relevantes para la norma jurídica y los hechos que aquellos describen.

Por lo tanto, la verdad entendida como correspondencia entre el supuesto de hecho de la norma jurídica y la realidad, ocupa un lugar trascendental en el proceso penal, a tal punto que constituye su finalidad más importante pues es la más adecuada al principio de legalidad y a los fines de la administración de justicia en un Estado social y democrático de derecho ${ }^{96}$. Esta finalidad, desde luego, busca

96 Los fines del proceso penal están ligados a los de la prueba. Estos “apuntan a la aproximación razonable a la verdad, en el entendido [de] que debe existir armonía entre los hechos referidos por las partes en sus enunciados y aquellos acaecidos y que esa correspondencia suministra el fundamento para la convicción con base en la cual el juez toma sus decisiones; a la realización de la justicia, entendida esta como el acceso a la administración de justicia y, a través de 
preservarse como última opción dentro del proceso penal con el recurso extraordinario de casación cuando se acude a las causales que tipifican la violación indirecta de la norma sustancial.

No se puede desconocer, por último, la trascendencia de la que está investido el recurso extraordinario, si se lo concibe como mecanismo de amparo constitucional, convencional y legal encaminado a la realización efectiva de los derechos fundamentales previstos en la Constitución y al respeto por las "garantías", entendidas estas como técnicas jurídicas de tutela de los derechos fundamentales ${ }^{97}$, si se tienen en cuenta como finalidades concretas de la casación penal la efectividad del derecho material y el respeto de las garantías de los intervinientes. Ciertamente, los falsos juicios de existencia, de identidad y de raciocinio atentan contra el derecho fundamental a la defensa y al acceso efectivo a la administración de justicia ${ }^{98}$, si se trata de pruebas aportadas por la defensa técnica no valoradas, distorsionadas en su contenido o valoradas sin apoyo en la sana crítica; por lo demás, se afectarían garantías propias del debido proceso constitucional previsto en el artículo 29 de la Carta Política, como el derecho a la prueba (previsto en el inciso 4 del artículo, en el que deben comprenderse sus componentes de aseguramiento,

esta, la concreción de los efectos previstos en las normas sustanciales; al estricto respeto de los derechos de los distintos intervinientes (...)”. JosÉ JOAQuín URBANO-MARTínez, La nueva estructura probatoria del proceso penal. Hacia una propuesta de fundamentación del sistema acusatorio, 114 (Ediciones Nueva Jurídica, Bogotá, 2012). Desde esta perspectiva, la finalidad de la prueba debe apuntar a suministrarle al juez el conocimiento, lo más fiable posible, de los supuestos fácticos que han de soportar su decisión, por lo que entonces se trata de obtener una verdad razonable (sin pretensiones de sujeción "absoluta" a la historia de los hechos pero tampoco sujeta a la libre recreación de las partes), atada sobre todo a la necesidad de fundamentación fáctica que en cada caso se le plantea a la jurisdicción, y a unos límites normativos, operacionales y temporales ineludibles. JosÉ JOAQUÍn URBANO-MARTínEZ, La nueva estructura probatoria del proceso penal. Hacia una propuesta de fundamentación del sistema acusatorio, 115 (Ediciones Nueva Jurídica, Bogotá, 2012). Ahora bien, la relación de la verdad con la justicia en el proceso penal ha sido planteada por la jurisprudencia de la Corte Constitucional en estos términos: "La verdad en el proceso penal es un presupuesto de la justicia, y por consiguiente, no es un asunto neutro o indiferente en la Constitución, sino una premisa fundamental en el ordenamiento superior que realiza y legitima el Estado". Corte Constitucional, Sentencia C-396-07, 23 de mayo de 2007, magistrado ponente Marco Gerardo Monroy-Cabra. Disponible en: http://www.corteconstitucional.gov.co/RELATORIA/2007/C-396-07.htm

97 La garantía es una expresión del léxico jurídico con la que se designa cualquier técnica jurídica normativa de tutela de un derecho subjetivo. Luigi Ferrajoli, Democracia y garantismo, 175-203 (Trotta, Madrid, 2008).

98 Artículo 229, Colombia, Constitución Política, versión corregida 116 Gaceta Constitucional, 20 de julio de 1991. Disponible en: http://www.secretariasenado.gov.co/senado/basedoc/ constitucion_politica_1991.html 
solicitud, decreto, práctica y valoración ${ }^{99}$ ), la presunción de inocencia y la prevalencia del derecho sustancial ${ }^{100}$ con la aplicación correcta de la norma jurídico-penal a partir de la acreditación de la verdad de sus supuestos de hecho.

Con miras a concebir una metodología adecuada a la consecución de estas finalidades, se concluye lo siguiente:

a. La actividad de valoración probatoria busca determinar el grado de corroboración de las hipótesis planteadas, en relación con las pruebas disponibles en el proceso; estas deben ser consideradas individualmente, y analizadas en conjunto.

b. El hecho de que se soslaye la prueba con su mención genérica configura el error de hecho por falso juicio de existencia, ya que en este caso el juez no le dedica la debida atención que le impone la labor de apreciación del caudal probatorio. Una motivación racional de la prueba implica evitar enunciaciones genéricas sin análisis ni justificación.

c. La preparación que supone la elaboración de una demanda de casación implica el estudio de las dos sentencias, porque la sentencia de primera instancia cubre las falencias y silencios de la decisión de segunda instancia, en lo no revocado por esta última.

d. Desde el punto de vista metodológico, en el planteamiento de los falsos juicios de existencia y de identidad, es importante que el casacionista se atenga rigurosamente al contenido de las pruebas no tenidas en cuenta o tergiversadas por el sentenciador, para derivar de ellas un convencimiento natural que cualquier otro observador racional pudiera tener, evitando esforzados razonamientos, y sin perder nunca de vista el principio de trascendencia, explicando de qué manera, y teniendo en cuenta las

99 Debe resaltarse la proyección constitucional del derecho a la prueba. Así, "el derecho a la prueba es un derecho negativo que implica la obligación correlativa del Estado frente al titular de ese derecho consistente en un no hacer; abstenerse de vulnerar el derecho de la parte al aseguramiento, la proposición, admisión y valoración racional de la prueba. Simultáneamente, implica una obligación positiva por parte del Estado de contribuir a la efectividad de este derecho y de los valores que representa (...)". Luis Bernardo Ruiz-Jaramillo, El derecho a la prueba como un derecho fundamental, 64 Revista Estudios de Derecho, 143, 181-206, 194 (2007). Disponible en: http://aprendeenlinea.udea.edu.co/revistas/index.php/red/article/ view/2552/2076

100 Artículo 228, Colombia, Constitución Política, versión corregida 116 Gaceta Constitucional, 20 de julio de 1991. Disponible en: http://www.secretariasenado.gov.co/senado/basedoc/ constitucion_politica_1991.html 
demás pruebas valoradas por las instancias, las conclusiones de la sentencia hubieran variado sustancialmente si no se hubiera omitido o malinterpretado la prueba. Este proceder es la vía para evitar la inadmisión de esta clase de cargos por apreciaciones puramente personales sobre el modo en que debió valorarse la prueba.

e. La jurisprudencia debe procurar una enseñanza simple de la técnica de casación para facilitar el acceso al recurso y evitar inadmisiones injustas, generadas quizás por un excesivo formalismo y la reiteración de farragosas metodologías.

f. Cuando se plantea un error de hecho por falso juicio de identidad, es importante delimitar claramente lo que le hizo decir el juzgador a la prueba, y lo que en realidad dice la prueba; esto para inferir cuál fue el contenido de la prueba ignorado, adicionado o tergiversado, ateniéndose siempre el casacionista al hecho genuino que se deriva de la prueba.

g. Es necesario definir en la demanda de casación las normas medio sobre apreciación probatoria que fueron infringidas, y que condujeron a la violación de las normas sustanciales en los sentidos de falta de aplicación o aplicación indebida: en este capítulo, debería entrar en juego la dogmática jurídico-penal aplicable al caso, que desafortunadamente no es hoy un acápite prioritario en las sentencias de la Corte de Casación.

h. Las censuras que invocan un falso raciocinio pero se limitan a controvertir el razonamiento con el que el sentenciador finalmente concluye sobre la inocencia o la culpabilidad, imponiendo puntos de vista subjetivos sobre la forma en que debió valorarse la prueba, están destinadas a la inadmisión, porque se trata de la fijación de un error protuberante en cuanto al desconocimiento de las reglas de la sana crítica, que tenga la potencialidad de variar las conclusiones de la decisión.

i. La expectativa es que la jurisprudencia de la Sala Penal consolide, en relación con las máximas de la experiencia, tres elementos: primero, una definición que no se centre exclusivamente en la noción de universalidad, porque también puede haber máximas de la experiencia particulares de un conglomerado social; segundo, una metodología que desarrolle la carga del casacionista de demostrar la existencia de la máxima de la experiencia invocada 
como no tenida en cuenta por las instancias; y tercero, una sistematización de las máximas más frecuentes según los delitos.

j. Si se parte de que la Corte de Casación debe controlar — si encuentra probados los falsos juicios que componen la vía indirecta de casación - la valoración del fallo de segunda instancia, debe tener en cuenta la racionalidad de la motivación, que está dada por criterios como el examen individual y en conjunto de la prueba, la exteriorización de las razones que justifican el mérito probatorio $y$, en relación con el juicio de culpabilidad jurídicopenal, la verificación de la coherencia de los hechos probados de la hipótesis acusatoria, y la imposibilidad de mantener vigente la hipótesis compatible con la inocencia del acusado, toda vez que puede haber pruebas omitidas o tergiversadas que refuten esa coherencia, y permitan concebir la imposibilidad de desvirtuar la presunción de inocencia.

k. La sana crítica en la Ley 600 de 2000 constituye el sistema de valoración probatoria; su vigencia en la Ley 906 de 2004 ha sido aceptada por la jurisprudencia, a pesar de las críticas de algún sector doctrinal, que concibe la vigencia del método de apreciación técnico-científica con fundamento en las normas procesales que definen los criterios de apreciación de los distintos medios de prueba. Al margen de esta discusión, que amerita una investigación más profunda, los sentenciadores están llamados a aplicar las reglas de la sana crítica y sus ejercicios plasmados en la Ley 906 de 2004, por lo que su demostrable desuso en la sentencia podría invocarse en casación mediante la causal de falso raciocinio.

1. El modelo cognoscitivista obedece a una actitud epistemológica que plantea una noción de verdad como correspondencia entre los enunciados fácticos relevantes para la aplicación del tipo penal y la realidad, y permite pensar en la falsibilidad o posibilidad de error de las hipótesis en el proceso, lo cual es viable en sede del recurso extraordinario de casación por medio de las causales de falso juicio de existencia, falso juicio de identidad y falso raciocinio. La técnica señalada por la jurisprudencia penal es viable si se interpreta con fundamento en este modelo, y se consideran los demás criterios sugeridos en este artículo, teniendo presente la necesaria erradicación de ciertas prácticas habituales 
de la Sala Penal de la Corte Suprema de Justicia al resolver las demandas de casación: deficiente lectura del expediente, meras réplicas basadas en la reproducción de los apartes de la sentencia del tribunal, olvido de la dogmática penal y defensa muchas veces acrítica de lo decidido por el ad quem, sin cotejo alguno de la demanda con el expediente. 


\section{BIBLIOGRAFÍA}

\section{Libros}

Aristóteles, Metafísica (Alianza Editorial, Madrid, 2011).

Beccaria, Cesare, Dei delitti e delle pene (Stamperia di Pietro Bizzoni successo a Bolzani, Pavia, 1817). Edición digital disponible en: http://bepi1949.altervista.org/delitti/ index.html, http://bepi1949.altervista.org/delitti/Cap14.htm

Brichetti, Giovanni, La "evidencia” en el derecho procesal penal (Ediciones Jurídicas Europa-América, Buenos Aires, 1973).

CAlderón-Botero, Fabio, Casación y revisión en materia penal (Librería del Profesional, Bogotá, 1985).

CAstillo-Alva, José Luis, La motivación de la valoración de la prueba en materia penal (Grijley \& Estudio Penal Castillo Alva \& Abogados, Lima, 2013).

Comanducci, Paolo, Razonamiento jurídico. Elementos para un modelo (Fontamara, México, 2004).

Couture, Eduardo Juan, Fundamentos del derecho procesal civil (Depalma, Buenos Aires, 1962).

Cuello-Iriarte, Gustavo, Derecho probatorio y pruebas penales (Legis, Bogotá, 2008).

Cuello-Iriarte, Gustavo, La sana crítica, sistema de valoración de la prueba judicial (Pontificia Universidad Javeriana, Bogotá, 2007).

Devis-Echandía, Hernando, Compendio de derecho procesal, Tomo II, Pruebas judiciales (Editorial ABC, Bogotá, 1973).

Devis-Echandía, Hernando, Teoría general de la prueba judicial, Tomo I (Temis, Bogotá, 2006).

Ferrajoli, Luigi, Democracia y garantismo (Trotta, Madrid, 2008).

Ferrajoli, Luigi, Derecho y razón. Teoría del garantismo penal (Trotta, Barcelona, 1997).

Ferrater-Mora, José, Diccionario de filosofía, Tomo I (Editorial Ariel, Barcelona, 2002).

Ferrer-Beltrán, Jordi, La valoración racional de la prueba (Marcial Pons, Madrid, 2007).

Framarino dei Malatesta, Nicola, Lógica de las pruebas en materia criminal, Tomo I (Temis, Bogotá, 2002).

Gascón-Abellán, Marina, Los hechos en el derecho, bases argumentales de la prueba (Marcial Pons, Madrid, 2010).

Gimbernat-Ordeig, Enrique, Estudios de derecho penal (Tecnos, Madrid, 1990).

Gorphe, Françors, Apreciación judicial de las pruebas: ensayo de un método técnico (Temis, Madrid, 1947-2004).

Helvétius, Claude-Adrien, Del espíritu (Laetoli, Pamplona, 2012).

Igartua-Salaverría, Juan, Valoración de la prueba, motivación y control en el proceso 
penal (Tirant lo Blanch, Valencia, 1995).

Montaigne, Michel de, Los ensayos (según la edición de 1595 de Marie de Gournay (Acantilado, Barcelona, 2007).

Morales-Marín, Gustavo, Ciencia de las pruebas penales. Sistema acusatorio (Grupo Editorial Ibáñez, Bogotá, 2014).

Morales-Molina, Hernando, Técnica de casación civil (Lerner, Bogotá, 1963).

Moreno-Rivera, Luis Gustavo, La casación en la ley 906 de 2004. Teoría y práctica bajo la nueva orientación constitucional (Ediciones Nueva Jurídica, Bogotá, 2013).

Nieva-Fenoll, Jordi, La valoración de la prueba (Marcial Pons, Madrid, 2010).

PABÓN-Gómez, Germán, De la casación en el sistema acusatorio (Grupo Editorial Ibáñez, Universidad de los Andes, Bogotá, 2011).

Pabón-Gómez, Germán, De la casación y la revisión penal en el Estado constitucional, social y democrático de derecho (Ediciones Doctrina y Ley, Bogotá, 2003).

Parra-QuiJano, JaIro, Manual de derecho probatorio (Ediciones Librería del Profesional, Bogotá, 2009).

Pérez-Pinzón, Álvaro Orlando, Introducción al estudio de la casación penal (Temis, Bogotá, 2014).

Ragués i Vallès, Ramón, El dolo y su prueba en el proceso penal (José María Bosch Editor, Barcelona, 1999).

Ramírez-Bastidas, Yesid, Casación penal (Leyer, Bogotá, 2011).

SÁnchez-Vera Gómez-Trelles, Javier, Variaciones sobre la presunción de inocencia. Análisis funcional desde el derecho penal (Marcial Pons, Madrid, 2012).

TARuffo, Michele, La prueba de los hechos (Trotta, Madrid, 2005).

TARuffo, Michele, Simplemente la verdad. El juez y la construcción de los hechos (DANiEla Accatino-Scagliotti, trad., Marcial Pons, Madrid, 2010).

Urbano-Martínez, José JoAquín, La nueva estructura probatoria del proceso penal. Hacia una propuesta de fundamentación del sistema acusatorio (Ediciones Nueva Jurídica, Bogotá, 2012).

Vattimo, Gianni, Adiós a la verdad (Gedisa, Barcelona, 2010).

Wigmore, John Henry, A Treatise on the Anglo-American System of Evidence in Trials at Common Law (Little, Brown \& Company, Boston, 1898-1940).

\section{Colaboración en obras colectivas}

TARuffo, Michele, Consideraciones sobre prueba y motivación, en Nuevas tendencias del derecho probatorio, 41-56 (Horacio Cruz-Tejada, ed., Universidad de los Andes, Bogotá, 2011). 


\section{Revistas, publicaciones periódicas}

Bacigalupo-Zapater, Enrique, Presunción de inocencia, "in dubio pro reo" y recurso de casación, Tomo 41 Anuario de Derecho Penal y Ciencias Penales, 2, 365-386 (1988). Disponible en: https://dialnet.unirioja.es/descarga/articulo/46325.pdf

RAGUÉS I VAllès, RAmón, Consideraciones sobre la prueba del dolo, 4 Revista de Estudios de la Justicia, REJ, 13-26 (2004). Disponible en: http://web.derecho.uchile.cl/cej/ recej/recej4/archivos/PRUEBA\%20DEL\%20DOLO\%20RAGUES\%20_8_.pdf

Ruiz-Jaramillo, Luis Bernardo, El derecho a la prueba como un derecho fundamental, 64 Revista Estudios de Derecho, 143, 181-206 (2007). Disponible en: http:// aprendeenlinea.udea.edu.co/revistas/index.php/red/article/view/2552/2076

Taruffo, Michele, La valutazione della prova. Prova libera e prova legale. Prove e argomenti di prova, 108 Quaderni del Consiglio Superiore della Magistratura, La prova nel Processo Civile, Volume Secondo, 423-446 (1999). Disponible en: http:// www.csm.it/quaderni/quad_108/quad_108_25.pdf

Velásquez-Velásquez, Fernando \& Wolffhügel-Gutiérrez, Christian, La diferencia entre el dolo eventual y la culpa consciente en la reciente jurisprudencia, 6 Cuadernos de Derecho Penal, 99-181 (2011). Disponible en: http://revistas.usergioarboleda. edu.co/index.php/cuadernos_de_derecho_penal/article/viewFile/395/342

\section{Normatividad internacional}

España, Ley de Enjuiciamiento Civil (Imprenta del Ministerio de Gracia y Justicia, Madrid, 1855). Edición digital de la Universidad de Sevilla. Disponible en: http:// fama2.us.es/fde/ocr/2006/leyDeEnjuiciamientoCivil1855.pdf

\section{Normatividad colombiana}

Colombia, Constitución Política, versión corregida 116 Gaceta Constitucional, 20 de julio de 1991. Disponible en: http://www.secretariasenado.gov.co/senado/basedoc/ constitucion_politica_1991.html

Colombia, Decreto 1400 de 1970, por el cual se expide el Código de Procedimiento Civil, 33.150 Diario Oficial, 21 de septiembre de 1970. Disponible en: http://www. alcaldiabogota.gov.co/sisjur/normas/Norma1.jsp?i=6923

Colombia, Ley 105 de 1931, Código Judicial, sobre organización judicial y procedimiento civil, 21.823 Diario Oficial, 24 de octubre de 1931. Disponible en: http://www. icbf.gov.co/cargues/avance/docs/ley_0105_1931.htm

Colombia, Ley 599 de 2000, por la cual se expide el Código Penal, 44.097 Diario Oficial, 24 de julio de 2000. Disponible en: http://www.secretariasenado.gov.co/senado/ basedoc/ley_0599_2000.html

Colombia, Ley 600 de 2000, por la cual se expide el Código de Procedimiento Penal, 44.097 Diario Oficial, 24 de julio de 2000. Disponible en: http://www. secretariasenado.gov.co/senado/basedoc/ley_0600_2000_pr004.html 
Colombia, Ley 906 de 2004, por la cual se expide el Código de Procedimiento Penal, 45.657 Diario Oficial, 31 de agosto de 2004. Disponible en: http://www. secretariasenado.gov.co/senado/basedoc/ley_0906_2004.html

\section{Jurisprudencia colombiana}

Corte Constitucional, Sentencia C-396-07, 23 de mayo de 2007, magistrado ponente Marco Gerardo Monroy-Cabra. Disponible en: http://www.corteconstitucional. gov.co/RELATORIA/2007/C-396-07.htm

Corte Constitucional de Colombia, Sentencia SU635-15, 7 de octubre de 2015, magistrado ponente Jorge Ignacio Pretelt-Chaljub. Disponible en: http://www. corteconstitucional.gov.co/relatoria/2015/su635-15.htm

Corte Constitucional, Sentencia T-1100-08, 6 de noviembre de 2008, magistrado ponente Humberto Antonio Sierra-Porto. Disponible en: http://www.corteconstitucional. gov.co/relatoria/2008/t-1100-08.htm

Corte Suprema de Justicia, Sala Penal, Proceso 19052, 9 de julio de 1985, magistrado ponente Hernando Baquero-Borda.

Corte Suprema de Justicia, Sala Penal, 24 de septiembre de 1985, magistrado ponente Fabio Calderón-Botero.

Corte Suprema de Justicia, Sala Penal Proceso 278, 27 de octubre de 1986, magistrado ponente Lisandro Martínez-Zúñiga.

Corte Suprema de Justicia, Sala Penal, Proceso 367, 10 de febrero de 1987, magistrado ponente Guillermo Duque-Ruiz.

Corte Suprema de Justicia, Sala Penal, Proceso 1118, 17 de junio de 1987, magistrado ponente Jaime Giraldo-Ángel.

Corte Suprema de Justicia, Sala Penal, Proceso 4649, 13 de julio de 1990, magistrado ponente Jaime Giraldo-Ángel.

Corte Suprema de Justicia, Sala Penal, Proceso 9428, 2 de octubre de 1996, magistrado ponente Carlos Augusto Gálvez-Argote. CCXLV Gaceta Judicial, Tomo 2484, 95-108. Disponible en: http://190.24.134.97/WebRelatoria/csj/index.xhtml

Corte Suprema de Justicia, Sala Penal, Proceso 10115, 7 de octubre de 1997, magistrado ponente Fernando Enrique Arboleda-Ripoll. Disponible en: http://190.24.134.97/ WebRelatoria/csj/index.xhtml

Corte Suprema de Justicia, Sala Penal, Proceso 12601, 18 de julio de 2000, magistrado ponente Fernando Enrique Arboleda-Ripoll. Disponible en: http://190.24.134.97/ WebRelatoria/csj/index.xhtml

Corte Suprema de Justicia, Sala Penal, Proceso 14961, 7 de septiembre de 2000, magistrado ponente Fernando Enrique Arboleda-Ripoll. Disponible en: http://190.24.134.97/WebRelatoria/csj/index.xhtml

Corte Suprema de Justicia, Sala Penal, Proceso 12658, 18 de abril de 2002, magistrado ponente Jorge Aníbal Gómez-Gallego. Disponible en: http://190.24.134.97/ WebRelatoria/csj/index.xhtml 
Corte Suprema de Justicia, Sala Penal, Proceso 16472, 21 de noviembre de 2002, magistrado ponente Jorge Aníbal Gómez-Gallego. Disponible en: http://190.24.134.97/WebRelatoria/csj/index.xhtml

Corte Suprema de Justicia, Sala Penal, Proceso 19970, 27 de abril de 2005, magistrado ponente Édgar Lombana-Trujillo. Disponible en: http://190.24.134.97/ WebRelatoria/csj/index.xhtml

Corte Suprema de Justicia, Sala Penal, Proceso 23772, 3 de agosto de 2005, magistrado ponente Álvaro Orlando Pérez-Pinzón. Disponible en: http://190.24.134.97/ WebRelatoria/csj/index.xhtml

Corte Suprema de Justicia, Sala Penal, Proceso 19646, 20 de octubre de 2005, magistrado ponente Yesid Ramírez. Disponible en: http://190.24.134.97/WebRelatoria/csj/ index.xhtml

Corte Suprema de Justicia, Sala Penal, Proceso 25971, 28 de septiembre de 2006, magistrada ponente Marina Pulido de Barón. Disponible en: http://190.24.134.97/ WebRelatoria/csj/index.xhtml

Corte Suprema de Justicia, Sala Penal, Proceso 27227, 21 de mayo de 2009, magistrado ponente Jorge Luis Quintero-Milanés. Disponible en: http://190.24.134.97/ WebRelatoria/csj/index.xhtml

Corte Suprema de Justicia, Sala Penal, Proceso 21977, 1 de julio de 2009, magistrado ponente Julio Enrique Socha-Salamanca. Disponible en: http://190.24.134.97/ WebRelatoria/csj/index.xhtml

Corte Suprema de Justicia, Sala Penal, Proceso 31522, auto de 18 de noviembre de 2009, magistrado ponente José Leonidas Bustos-Martínez. Disponible en: http://190.24.134.97/WebRelatoria/csj/index.xhtml

Corte Suprema de Justicia, Sala Penal, Proceso 32722, 16 de junio de 2010, magistrado ponente José Leonidas Bustos-Martínez. Disponible en: http://190.24.134.97/ WebRelatoria/csj/index.xhtml

Corte Suprema de Justicia, Sala Penal, Proceso 32964, 25 de agosto de 2010, magistrado ponente José Leonidas Bustos-Martínez. Disponible en: http://190.24.134.97/ WebRelatoria/csj/index.xhtml

Corte Suprema de Justicia, Sala Penal, Proceso 32270, 29 de septiembre de 2010, magistrado ponente Yesid Ramírez-Bastidas. Disponible en: http://190.24.134.97/ WebRelatoria/csj/index.xhtml

Corte Suprema de Justicia, Sala Penal, Proceso 35621, auto de 2 de marzo de 2011, magistrado ponente Julio Enrique Socha-Salamanca. Disponible en: http://190.24.134.97/WebRelatoria/csj/index.xhtml

Corte Suprema de Justicia, Sala Penal, Proceso 38571, 16 de mayo de 2012, magistrado ponente Fernando Alberto Castro-Caballero. Disponible en: http://190.24.134.97/ WebRelatoria/csj/index.xhtml

Corte Suprema de Justicia, Sala Penal, Proceso 36824, 12 de septiembre de 2012, magistrado ponente Julio Socha-Salamanca. Disponible en: http://190.24.134.101/ corte/wp-content/uploads/relatorias/pe/bloct2012/36824(12-09-12).doc

Corte Suprema de Justicia, Sala Penal, Proceso 35161, 6 de marzo de 2013, magistrado 
ponente Julio Enrique Socha-Salamanca. Disponible en: http://190.24.134.97/ WebRelatoria/csj/index.xhtml

Corte Suprema de Justicia, Sala Penal, Proceso 40431, 24 de abril de 2013, magistrado ponente José Luis Barceló-Camacho. Disponible en: http://190.24.134.97/ WebRelatoria/csj/index.xhtml

Corte Suprema de Justicia, Sala Penal, Proceso 37626, 13 de noviembre de 2013, magistrado ponente José Leonidas Bustos-Martínez. Disponible en: http://190.24.134.97/WebRelatoria/csj/index.xhtml

Corte Suprema de Justicia, Sala Penal, Proceso 43033, 5 de marzo de 2014, magistrado ponente Fernando Alberto Castro-Caballero. Disponible en: http://190.24.134.97/ WebRelatoria/csj/index.xhtml

Corte Suprema de Justicia, Sala Penal, Proceso 41800, 16 de julio de 2014, magistrado ponente Gustavo Enrique Malo-Fernández. Disponible en: http://190.24.134.97/ WebRelatoria/csj/index.xhtml

Corte Suprema de Justicia, Sala Penal, Proceso 44639, 19 de agosto de 2015, magistrado ponente Eyder Patiño-Cabrera. Disponible en: http://190.24.134.97/WebRelatoria/ csj/index.xhtml

Corte Suprema de Justicia, Sala Penal, Proceso 37047, 26 de agosto de 2015, magistrado ponente Eugenio Fernández-Carlier. Disponible en: http://190.24.134.97/ WebRelatoria/csj/index.xhtml

Corte Suprema de Justicia, Sala Penal, Proceso 46483, 9 de marzo de 2016, magistrado ponente Luis Guillermo Salazar-Otero. Disponible en: http://190.24.134.97/ WebRelatoria/csj/index.xhtml 
